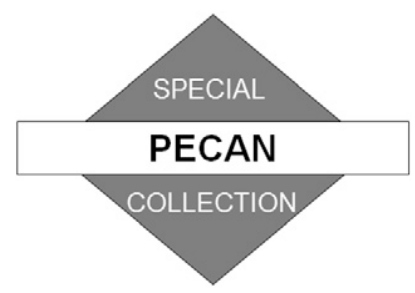

\title{
A Composite Perspective on Bore Passages during the PECAN Campaign
}

\author{
DAVID M. LOVELESS \\ Department of Atmospheric and Oceanic Sciences, and Space Science and Engineering Center/Cooperative Institute \\ for Meteorological Satellite Studies, University of Wisconsin-Madison, Madison, Wisconsin \\ TIMOTHY J. WAGNER \\ Space Science and Engineering Center/Cooperative Institute for Meteorological Satellite Studies, University of \\ Wisconsin-Madison, Madison, Wisconsin \\ DAVID D. TURNER \\ Global Systems Division, NOAA/Earth System Research Laboratory, Boulder, Colorado \\ STEVEN A. ACKERMAN \\ Department of Atmospheric and Oceanic Sciences, and Space Science and Engineering Center/Cooperative Institute \\ for Meteorological Satellite Studies, University of Wisconsin-Madison, Madison, Wisconsin

\section{WAYNE F. FELTZ} \\ Space Science and Engineering Center/Cooperative Institute for Meteorological Satellite Studies, University of
} Wisconsin-Madison, Madison, Wisconsin

(Manuscript received 15 August 2018, in final form 7 February 2019)

\begin{abstract}
Atmospheric bores have been shown to have a role in the initiation and maintenance of elevated convection. Previous observational studies of bores have been case studies of more notable events. However, this creates a selection bias toward extraordinary cases, while discussions of the differences between bores that favor convective initiation and maintenance and bores that do not are lacking from the literature. This study attempts to fill that gap by analyzing a high-temporal-resolution thermodynamic profile composite of eight bores observed by multiple platforms during the Plains Elevated Convection at Night (PECAN) campaign in order to assess the impact of bores on the environment. The time-height cross section of the potential temperature composite displays quasi-permanent parcel displacements up to $900 \mathrm{~m}$ with the bore passage. Low-level lifting is shown to weaken the capping inversion and reduce convective inhibition (CIN) and the level of free convection (LFC). Additionally, low-level water vapor increases by about $1 \mathrm{~g} \mathrm{~kg}^{-1}$ in the composite mean. By assessing variability across the eight cases, it is shown that increases in low-level water vapor result in increases to convective available potential energy (CAPE), while drying results in decreased CAPE. Most cases resulted in decreased CIN and LFC height with the bore passage, but only some cases resulted in increased CAPE. This suggests that bores will increase the potential for convective initiation, but future research should be directed toward better understanding cases that result in increased CAPE as those are the types of bores that will increase severity of convection.
\end{abstract}

Corresponding author: David M. Loveless, dloveless@wisc. edu

\section{Introduction}

Convective weather produces as much as $70 \%$ of warm season precipitation in the central Great Plains of the United States (Fritsch et al. 1986), much of which happens at night (Wallace 1975; Heideman and Fritsch 1988; 
Colman 1990). Nocturnal convection typically occurs with a stable boundary layer and elevated instability. Infrared radiative cooling of the surface at night creates a stable nocturnal boundary layer, which reduces the amount of energy a convective cell is able to remove from the nocturnal boundary layer. This results in the layer with greatest instability being above the surface. One potential mechanism for initiating and maintaining elevated convection is atmospheric bores (Parker 2008; French and Parker 2010). Bores are a type of gravity wave that form from the interaction of a density current with a stable fluid of lesser density. Bores will form in either a partially blocked system (Rottman and Simpson 1989) or a completely blocked system (Parsons et al. 2019) and are frequently observed in the atmosphere when cold air from thunderstorm outflow undercuts a stable boundary layer (e.g., Koch et al. 1991; Knupp 2006; Koch et al. 2008). Wakimoto and Kingsmill (1995) have also observed the formation of a bore from the collision of a sea breeze and an outflow boundary. Cold fronts can also act as a density current and result in bore formation in the presence of a stable boundary layer (Koch and Clark 1999; Hartung et al. 2010).

A bore passage will result in a quasi-permanent surface pressure jump and a surface wind shift toward the direction of bore movement (e.g., Clarke et al. 1981; Smith 1988). Bores produce low-level lifting, which will lift the inversion to a quasi-permanent greater height (Koch et al. 1991; Knupp 2006; Koch et al. 2008). This lifting results in cooling of the lower troposphere (Koch et al. 1991, 2008), which causes the increase in surface pressure. Surface temperature changes range from negligible (Smith 1988; Mahapatra et al. 1991) to increases in temperature as a result of adiabatic mixing of warm air at the level of the inversion down to the cooler surface (Clarke et al. 1981; Koch et al. 1991). Surface drying and cooling will happen with the arrival of the gravity current following the bore (Koch et al. 1991; Koch and Clark 1999; Toms et al. 2017).

The magnitude of the vertical displacements of parcels due to this lifting has been reported to be as large as $2000 \mathrm{~m}$ (Knupp 2006), while Parsons et al. (2019) identified an average of $900 \mathrm{~m}$ using 13 cases. Mechanical lifting caused by bore passages frequently results in cloud formation (e.g., Clarke et al. 1981; Smith et al. 1982; Knupp 2006; Coleman et al. 2010) and may trigger convective initiation if parcels are lifted to their level of free convection (LFC) (Karyampudi et al. 1995; Locatelli et al. 2002; Koch et al. 2008).

Studies by Knupp (2006) and Koch et al. (2008) have suggested that bores will change their characteristics over the course of their lifetimes. Koch et al. (2008) used a combination of observations and numerical simulations to identify changes in the turbulent nature of the bore over the course of its life cycle. They identified that the majority of turbulent kinetic energy is generated by the shear stress from the strong along-bore flow associated with the low-level jet (LLJ). Additionally, they found that early in the life cycle of the bore, in what they called the "active phase," turbulent mixing is greater. In the case they studied, this resulted in dry air mixing downward to the surface behind the bore. Later in the life cycle, in the "dissipation stage," the turbulent mixing is weaker, and this resulted in moist air being distributed throughout the depth of the bore. Different mixing patterns of bores have been confirmed by Tanamachi et al. (2008), in which rapid drying and moistening events in the boundary layer were observed and concluded to be bores. Knupp (2006) studied the evolution of a bore transitioning into a solitary wave and observed that the bore's propagation speed decreased as it moved into a region with greater boundary layer stability. As the bore slowed down, the bore strength (a ratio of the bore depth to the prebore inversion depth) decreased and eventually the bore transitioned into a solitary wave. The quasi-permanent parcel displacements and pressure changes of a bore differentiate it from a solitary wave, in that a solitary wave will oscillate to a maximum and return to the preexisting level or value (Christie et al. 1978; Christie 1989; Knupp 2006).

The lifting and mixing processes associated with bore passages have been observed to weaken the capping inversion and destabilize the boundary layer (Koch et al. 1991, 2008; Coleman and Knupp 2011). Coleman and Knupp (2011) used temperature and water vapor retrievals from a microwave profiling radiometer to make time series of convective available potential energy (CAPE) and convective inhibition (CIN) during a bore passage and observed a decrease in surface-based CIN coupled with an increase in $300 \mathrm{~m}$ above ground level (AGL) CAPE at the time of the bore passage. Convective initiation was observed in the vicinity of this bore and associated solitons. Numerous studies have shown that bores play a role in initiating convection based on both observations (Koch and Clark 1999; Wilson and Roberts 2006; Haghi et al. 2017) and numerical simulations (Karyampudi et al. 1995; Locatelli et al. 2002). Model simulations of squall lines by Parker (2008) and French and Parker (2010) suggest that atmospheric bores play an important role in maintaining multicellular convection as the instability becomes elevated.

As demonstrated above, much of the existing understanding of bores and their impacts on the environment comes from the investigation of specific cases, either through observations, modeling, or a combination of the 
two. Case studies, however, are not necessarily representative of the phenomenon of bores as there is likely a selection bias toward extraordinary cases. The typical changes that bores make to the boundary layer and atmospheric stability have not yet been discussed beyond a case study. The present work seeks to address this issue by compositing the thermodynamic and kinematic profiles from a set of eight bores, each in a different stage of its life cycle, observed during the Plains Elevated Convection at Night (PECAN) field campaign. PECAN and the instrumentation used in this study will be discussed in the following section. This work documents the average evolution to the boundary layer and atmospheric stability with bore passages by creating both time-based and wavenumber-based composites of bore passages. The variability of boundary layer transitions and associated stability changes across the eight cases will also be displayed.

\section{Data and instrumentation}

\section{a. PECAN overview}

The PECAN (Geerts et al. 2017) field campaign took place from 1 June to 15 July 2015 in the central United States. The designated PECAN domain was northern Oklahoma, Kansas, and southern Nebraska, but observations were taken as far north as South Dakota and as far east as Indiana. PECAN was designed to advance the scientific understanding and forecast skill of the processes that initiate and maintain elevated nocturnal convection in the Great Plains, and one of the focal points of the campaign was gaining a better understanding of bores and other boundary layer wave-like features and their relation to initiating and maintaining elevated convection.

The campaign featured a diverse suite of fixed and mobile observing platforms. Mobile platforms included mobile Doppler radars, aircraft, mobile GPS Advanced Upper-Air Sounding (GAUS) systems for radiosonde deployment, and remote sensing profiling units consisting of thermodynamic and kinematic profilers, surface observations, and radiosonde launches. The mobility of the instrumentation allowed for units to be deployed in position to observe necessary phenomena with short notice (as science team leaders may only be certain about the forecast a few hours in advance) and to fill gaps within existing instrumentation.

One of the unique aspects of the PECAN campaign as compared to previous field studies was the creation of the PECAN Integrated Sounding Array (PISA). There were 11 PISA units: six fixed profiling (FP) sites located throughout northern Oklahoma, Kansas, and southern Nebraska, and five mobile profiling (MP) units.
Each PISA platform made remotely sensed hightemporal-resolution kinematic and/or thermodynamic profile observations; additionally the majority of platforms had surface meteorology observations and radiosondes. The thermodynamic and kinematic profilers provided high-temporal-resolution observations of lowlevel temperature, water vapor, and wind, allowing for a complete observation of the evolution of lowertropospheric structure during the targeted weather events and enabling the assessment of the evolution of atmospheric stability (CIN, CAPE, etc.), water vapor transport, mesoscale convergence, and the structure and evolution of bores and solitary waves, all at high temporal resolution.

The work presented in this study utilizes observations from two fixed profiling (FP) sites, FP3 and FP4, as well as two mobile profiling units: the University of Oklahoma/National Severe Storms Laboratory Collaborative Lower Atmosphere Mobile Profiling System (CLAMPS), and the University of Wisconsin-Madison Space Science and Engineering Center (SSEC) Portable Atmosphere Research Center (SPARC) (Wagner et al. 2019). These PISA units were selected because each included an Atmospheric Emitted Radiance Interferometer (AERI; Knuteson et al. 2004a,b) as its thermodynamic profiling source, enabling uniformity in the thermodynamic observations across the different observation platforms. The instrumentation and respective data sources used in this study are displayed in Table 1 . While three other FP sites were part of the domain, siting and data issues limited the utility of the observations from these locations.

\section{b. Thermodynamic profiling}

The AERI is a passive ground-based interferometer that measures downwelling atmospheric radiation at $0.5 \mathrm{~cm}^{-1}$ resolution from 520 to $3000 \mathrm{~cm}^{-1}(19.2-$ $3.3 \mu \mathrm{m}$ ) (Knuteson et al. 2004a,b). The instrument makes upward sky views every 20-30 s and uses two blackbodies, one at ambient air temperature and one at $60^{\circ} \mathrm{C}$, to calibrate the system. This allows the system to obtain radiometric accuracy greater than $1 \%$ of the ambient radiance (Knuteson et al. 2004b), while a principal component analysis noise filter (Turner et al. 2006) is applied to reduce the random noise in the radiance observations.

From these radiances, the AERI optimal estimation algorithm (AERIoe; Turner and Löhnert 2014; Turner and Blumberg 2019) was used to retrieve thermodynamic profiles. While the radiance measurements were made at a temporal resolution of $30 \mathrm{~s}$, they were averaged to a 2-min resolution before the retrieval was applied; this temporal resolution balances the need for 
TABLE 1. Overview of the thermodynamic and kinematic profiling instrumentation used in this study.

\begin{tabular}{|c|c|c|c|c|}
\hline Instrument & Profiler type & Profiling unit & Location & Data source \\
\hline \multirow[t]{4}{*}{ AERI } & Thermodynamic & FP3 & Ellis, KS & Turner (2016a) \\
\hline & & FP4 & Minden, NE & Turner (2016b) \\
\hline & & CLAMPS (MP1) & Various & Turner (2016c) \\
\hline & & SPARC (MP3) & Various & Wagner et al. (2016a) \\
\hline $449 \mathrm{MHz}$ WP & Kinematic & FP3 & Ellis, KS & $\begin{array}{l}5 \text { min version of UCAR/NCAR Earth } \\
\text { Observing Laboratory (2017) }\end{array}$ \\
\hline $915 \mathrm{MHz}$ WP & Kinematic & FP4 & Minden, NE & $\begin{array}{l}5 \text { min version of UCAR/NCAR Earth } \\
\text { Observing Laboratory (2015) }\end{array}$ \\
\hline \multirow[t]{3}{*}{ Doppler lidar } & Kinematic & FP3 & Ellis, KS & Hanesiak and Turner (2016) \\
\hline & & CLAMPS (MP1) & Various & Turner (2016d) \\
\hline & & SPARC (MP3) & Various & Wagner et al. (2016b) \\
\hline
\end{tabular}

finely resolved profiles with further noise reduction. The physical retrieval technique used in this study is slightly different from the version described in Turner and Löhnert (2014). A climatology using several thousand radiosondes launched at the ARM Southern Great Plains (Sisterson et al. 2016) site in June and July is used as the a priori, and provides the level-to-level covariance matrix used to constrain the solution to physically realistic profiles. Hourly analyses from the Rapid Refresh Model (RAP; Benjamin et al. 2016) model above $4 \mathrm{~km}$ are also included in the observation vector to constrain the retrieved solution above this altitude where AERI has little information content on temperature or humidity (Turner and Löhnert 2014). This combination of information allows for better calculations of convective indices, such as convective available potential energy (CAPE), due to the more accurate upper-air representation. Using comparisons to radiosonde observations, Blumberg et al. (2017a) found that AERI retrievals are best suited for mixedlayer calculations, compared to surface-based and most-unstable parcel calculations. They conclude that calculations of convective indices from AERI retrievals may have large inaccuracies, but the good correlation between the convective indices derived from collocated radiosondes and AERI retrievals make the latter well suited to monitor and capture trends in atmospheric stability.

\section{c. Kinematic profiling}

While the focus of this study is on the thermodynamic characteristics of bores, the relationship between bores and vertical velocity changes were also explored as each PISA unit also contained one of a number of various types of vertical wind profilers. Depending on the facility, either a Doppler lidar, $449-\mathrm{MHz}$ wind profiler, or $915-\mathrm{MHz}$ wind profiler was available. All three profiler types rely on using the Doppler shift of backscattered radiation at multiple azimuths and/or elevations in order to reconstruct the three-dimensional wind field.

The Streamline Doppler lidar (HALO Photonics, United Kingdom; Pearson et al. 2009) uses a $1.5-\mu \mathrm{m}$ laser to remotely analyze wind speed and direction within the boundary layer. The lidar emits pulses at a rate of $20 \mathrm{kHz}$, which are backscattered by aerosols and clouds. During PECAN the lidars were configured to complete a series of 1-s vertical stare and an 8-point velocity-azimuth display (VAD) scan every $2 \mathrm{~min}$, during which the beam is pointed at a constant elevation angle, and rotated $360^{\circ}$, in order to assess vertical profiles of the three-dimensional wind vector. While the unambiguous range of the lidar is $7.5 \mathrm{~km}$, the available scatterers and cloud base limited the effective range to around $2000 \mathrm{~m}$ AGL during the campaign. These instruments were located with CLAMPS, SPARC, and at FP3 during the PECAN campaign. The lowest range gate is at $100 \mathrm{~m}$ AGL, with a vertical resolution of about $30 \mathrm{~m}$.

The FP4 site utilized a four-panel Scintec LAP$3000915-\mathrm{MHz}$ radar wind profiler to observe vertical profiles of the three-dimensional wind. The original design of the profiler is described in Ecklund et al. (1990). It uses a Doppler beam swinging technique to point the beam in three different orthogonal directions in order to make horizontal and vertical wind measurements, utilizing backscatter from turbulence generated temperature and water vapor inhomogeneities. Insects are also a source of backscatter for the $915-\mathrm{MHz}$ wind profiler, and tend to result in negative biases in updraft regions since they do not ascend with the vertical winds as other scattering sources do (Geerts and Miao 2005; Knupp et al. 2016). Data are postprocessed using the NCAR Improved Moments Algorithm (NIMA; Morse et al. 2002) to enable the retrieval of winds in weak or noisy data. Its maximum unambiguous height is $5 \mathrm{~km}$ (Scintec 2017) but typical viewing heights were only about $2.5 \mathrm{~km}$ for the 10 -min-averaged 
(using a 5-min update cycle) data used in this study. This is because of a combination of the reduction in signal-to-noise ratio with higher-temporal-resolution data and a lack of turbulent generated inhomogeneities above the boundary layer. The lowest observation level is $180 \mathrm{~m}$ AGL with a vertical resolution of $60 \mathrm{~m}$.

A $449-\mathrm{MHz}$ multiple antenna profile radar, with a seven antenna module configuration, was used at FP3. This system transmits and receives multiple pulses at once in different directions as opposed to using the traditional Doppler beam swinging method. Similar to the $915-\mathrm{MHz}$ profiler, the $449-\mathrm{MHz}$ profiler detects backscatter from temperature and humidity inhomogeneities generated by turbulence. The profiler can view up to $5 \mathrm{~km}$, but the typical maximum height of observations was $3 \mathrm{~km}$ for the 5 -min-averaged data used in this study. The phased array setup of the $449-\mathrm{MHz}$ profiler, along with the longer wavelength of the radar, results in better signal-to-noise ratio and allows for kinematic retrievals at greater heights and greater time resolution than the $915-\mathrm{MHz}$ profiler. In this configuration the vertical resolution was $60 \mathrm{~m}$ with the lowest range gate at $300 \mathrm{~m}$ AGL. A technical overview of the design and additional details on wind profiler performance may be found in Lindseth et al. (2012).

\section{Compositing method}

One of the drawbacks of current available literature available on bores is that the observational studies that describe boundary layer and stability changes have focused on single events. While Parsons et al. (2019) does not focus on a specific event, stability changes assessed in their study were based on what they described as "sparse sounding data" and only analyzed for two cases. Other studies have primarily focused on bores that have resulted in boundary layer transitions favorable for convective initiation and bores that result in convective initiation, primarily because they have the largest impacts and are the most intellectually stimulating. By creating a composite that includes bores that are both favorable and unfavorable for convection, the mean changes within the boundary layer caused by a bore passage can be identified and the role of bores in convective initiation may be better identified. By using high-temporal-resolution thermodynamic and kinematic profilers, changes to atmospheric conditions on time scales of only minutes may be detected.

Individual bore cases included in this composite were identified by verifying 1) a "fine-line" feature on radar in proximity to the observing platform and
2) a quasi-permanent jump in surface pressure at the PISA unit, corresponding closely in time with 3) low-level quasi-permanent isentropic ascent identified in AERIoe retrievals of potential temperature, and 4) negligible to small surface temperature changes or surface warming. This method identifies bores propagating ahead of the parent density current. A total of eight cases were observed by the FP3, FP4, CLAMPS, and SPARC observing platforms during PECAN that met our defining criteria.

Koch and Clark (1999) suggest comparing the observed and predicted bore speed, according to hydraulic theory, in order to prove that a feature is indeed a bore and not another type of gravity wave. Unfortunately, we had difficulties identifying the mean bore depth using AERIoe retrievals due to the decrease in vertical resolution with height (Turner and Löhnert 2014). Table 2 displays the eight bores included in this study from these observational platforms and some basic characteristics of each case. The net vertical parcel displacements estimated from the AERIoe retrievals are very similar to the observations shown by Parsons et al. (2019). Figure 1 displays the radar base reflectivity for each case, 20-30 min before the bore was observed at the respective observing platform. Qualitatively the majority of cases are mature bores, in that the bore is well separated from the parent precipitation and density current, but two of the cases (7 June FP4, 21 June FP4) observe the bore while it is still close to the parent precipitation and thus, the parent density current.

While some platforms observed bores on the same day, each case is a different bore (i.e., it was not a single bore that traveled over two observing sites). Numerous other gravity waves and bore-like features were observed by the PISA platforms, but did not meet the strict definitions we set as the defining criteria and may have either occurred in proximity to rain (in which case the AERI hatch is closed and does not make measurements) or were too close to the density current to be distinguished as a bore (surface cooling would occur with the density current). We used the $449-\mathrm{MHz}$ wind profiler for wind data on the 2 June case at FP3, and the Doppler lidar on 7 June at FP3. As of the time of this paper, the 20 June bore, observed at FP4, has been studied in greater detail in Mueller et al. (2017) and the 16 July bore, with SPARC, is included in Grasmick et al. (2018). Johnson et al. (2018) studied a bore-like wave on 11 July 2015 from PECAN observed by FP3, CLAMPS, and SPARC; however, the bore-like feature they studied resulted in surface cooling at those three observing sites and therefore did not meet our defining criteria. 


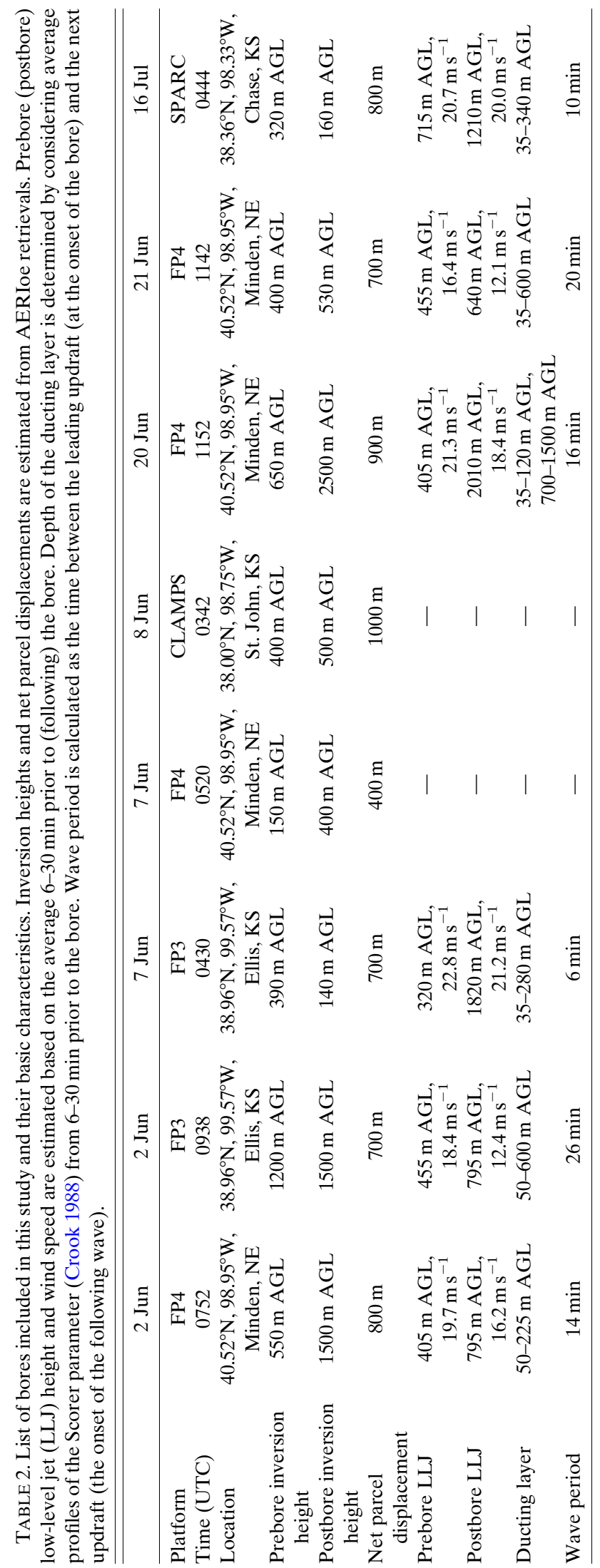



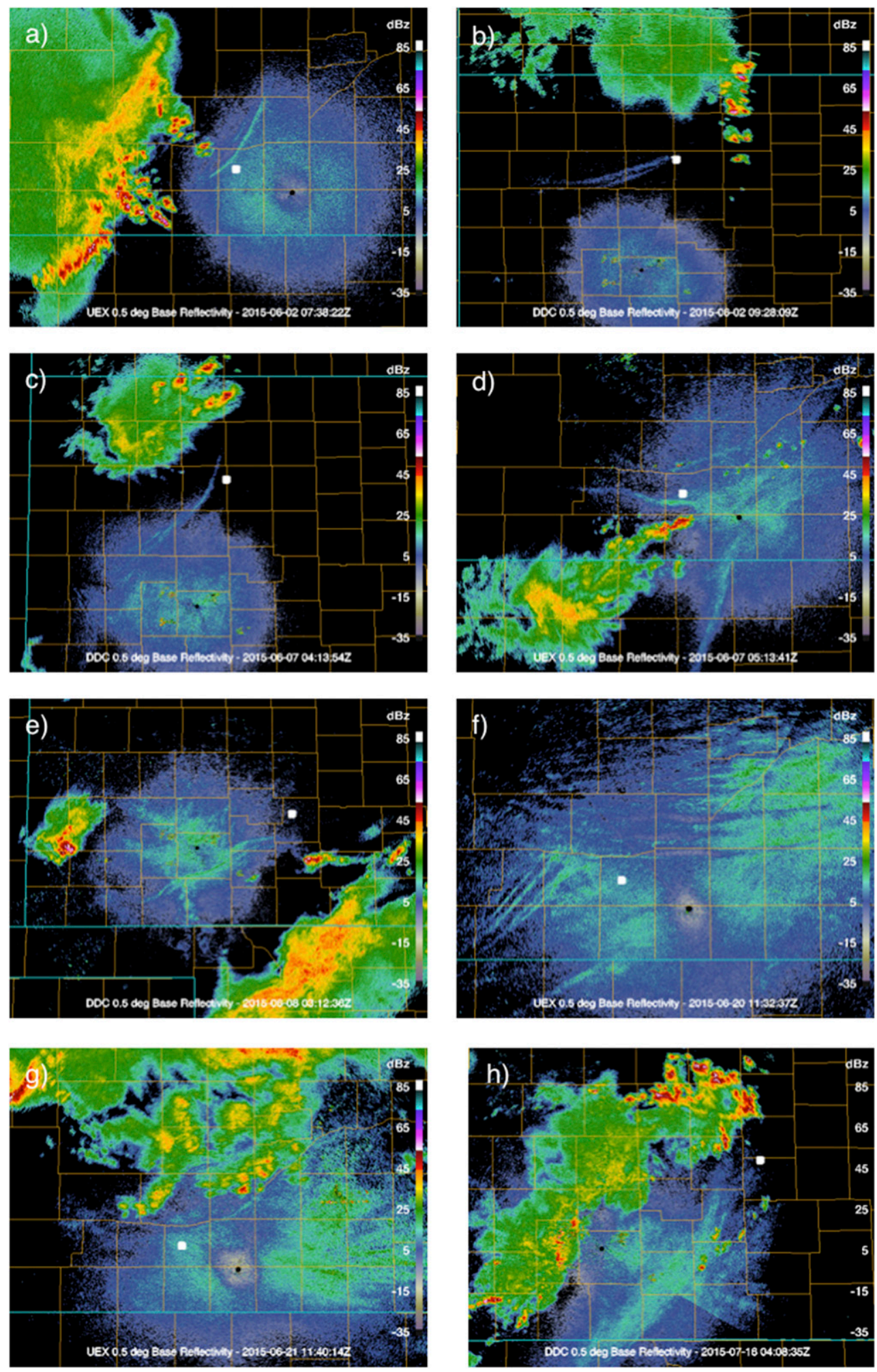

FIG. 1. Radar $0.5^{\circ}$ base reflectivity for (a) UEX at 0738 UTC 2 Jun 2015 (corresponds to case on 2 Jun 2015 at FP4), (b) DDC at 0928 UTC 2 Jun 2015 (corresponds to case on 2 Jun 2015 at FP3), (c) DDC at 0413 UTC 7 Jun 2015 (corresponds to case on 7 Jun 2015 at FP3), (d) UEX at 0513 UTC 7 Jun 2015 (corresponds to case on 7 Jun 2015 at FP4), (e) DDC at 0803 UTC 8 Jun 2015 (corresponds to case on 8 Jun 2015 at CLAMPS), (f) UEX at 1132 UTC 20 Jun 2015 (corresponds to case on 20 Jun 2015 at FP4), (g) UEX at 1140 UTC 21 Jun 2015 (corresponds to case on 21 Jun 2015 at FP4), (h) DDC at 0408 UTC 16 Jul 2015 (corresponds to case on 16 Jul 2015 at SPARC). In each figure, the location of the observing platform of interest is identified as the white dot. 
The kinematic and surface observations are all interpolated to the time and height grid of the thermodynamic AERIoe retrievals in order to provide uniformity when averaging. However, a start time of the bore must be identified to create such a composite. By considering factors related to bores, such as surface pressure, vertical velocity profiles, horizontal wind speed and direction (at the surface and profiles), and potential temperature profiles, a time range which a bore occurred is manually determined given knowledge of the expected temporal changes in these atmospheric variables. The start time is determined by finding the derivative of surface pressure with respect to time using a center finite differencing method throughout the preidentified time range and identifying the time of greatest increase in surface pressure, then identifying the maximum in column-averaged vertical velocity from 500 to $1500 \mathrm{~m}$ AGL within 6 min of that time; this facilitates alignment of the bores by their initial updrafts. The lack of wind data for the 8 June bore with CLAMPS and the 7 June bore with FP4 mean we use the time of the greatest increase in surface pressure as the start time. By identifying a start time, it is possible to create a bore-centric temporal frame of reference through which all bores can be analyzed. While a more sophisticated bore start time procedure could be developed, including objective analysis of surface pressure changes and wind shifts, inspection of the results indicates that the simpler method is sufficient for the goals of this study.

\section{Results}

\section{a. Time composite results}

Figure 2a displays the composite surface pressure anomaly (calculated by subtracting the value of that variable at the time of the bore passage from the total field) along with the surface pressure anomaly time series for each of the 8 individual cases; observations were available for at least $45 \mathrm{~min}$ before and after each bore with all but two cases having at least $60 \mathrm{~min}$ of data on each side. In the composite mean, there is a surface pressure increase on the order of $1.5 \mathrm{hPa}$ with the bore passage, with most of the cases showing pressure increases around that magnitude as well. This is consistent with surface pressure changes shown in numerous previous case studies (e.g., Clarke et al. 1981; Karyampudi et al. 1995; Koch and Clark 1999; Koch et al. 2008). Time series of surface temperature for each case and the composite mean are displayed in Fig. 2b. The composite mean shows a very gradual increase in surface temperature beginning at the onset of the bore and leveling off again $20 \mathrm{~min}$ after the bore for a total increase of $0.5^{\circ} \mathrm{C}$.
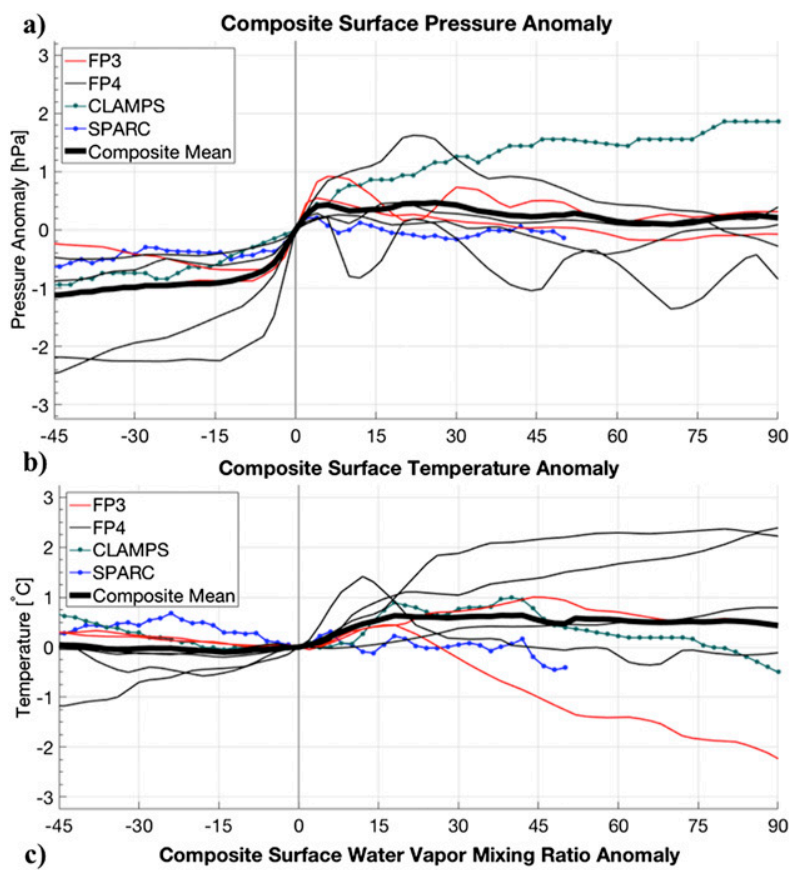

c) Composite Surface Water Vapor Mixing Ratio Anomaly

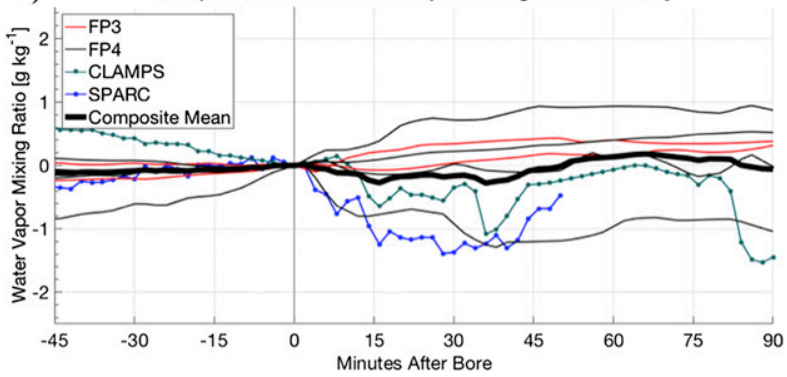

FIG. 2. Composite mean time series (thick line) of (a) surface pressure anomaly $(\mathrm{hPa}),(\mathrm{b})$ temperature $\left({ }^{\circ} \mathrm{C}\right)$, and $(\mathrm{c})$ water vapor mixing ratio $\left(\mathrm{g} \mathrm{kg}^{-1}\right)$. Time series of anomalies for each individual case are displayed by the thin lines, on the bore-centric time frame, displayed in each figure, colored according to observing platform. Anomalies are calculated by subtracting the value at the time of the bore passage from the total field.

Most cases are in the range of minimal changes to a $1^{\circ} \mathrm{C}$ increase in surface temperature with the bore passage; however, all three cases at FP4 experienced greater than a $1^{\circ} \mathrm{C}$ increase after the bore. One case with FP3 is an outlier in that the surface temperature ends up almost $2^{\circ} \mathrm{C}$ cooler $75 \mathrm{~min}$ after the bore compared the onset of the bore because of a density current arriving $20 \mathrm{~min}$ after the bore; this is the only case that observed a density within $90 \mathrm{~min}$ of the bore. By contrast, surface water vapor mixing ratio (Fig. 2c) displays much greater variability. While the composite mean reveals very slight surface drying, there is a nearly even spread of moistening and drying cases. Koch et al. (2008) catalogs the potential for bores to result in either moistening or drying of the boundary layer due to differences in turbulent mixing, and these cases reinforce that finding. 

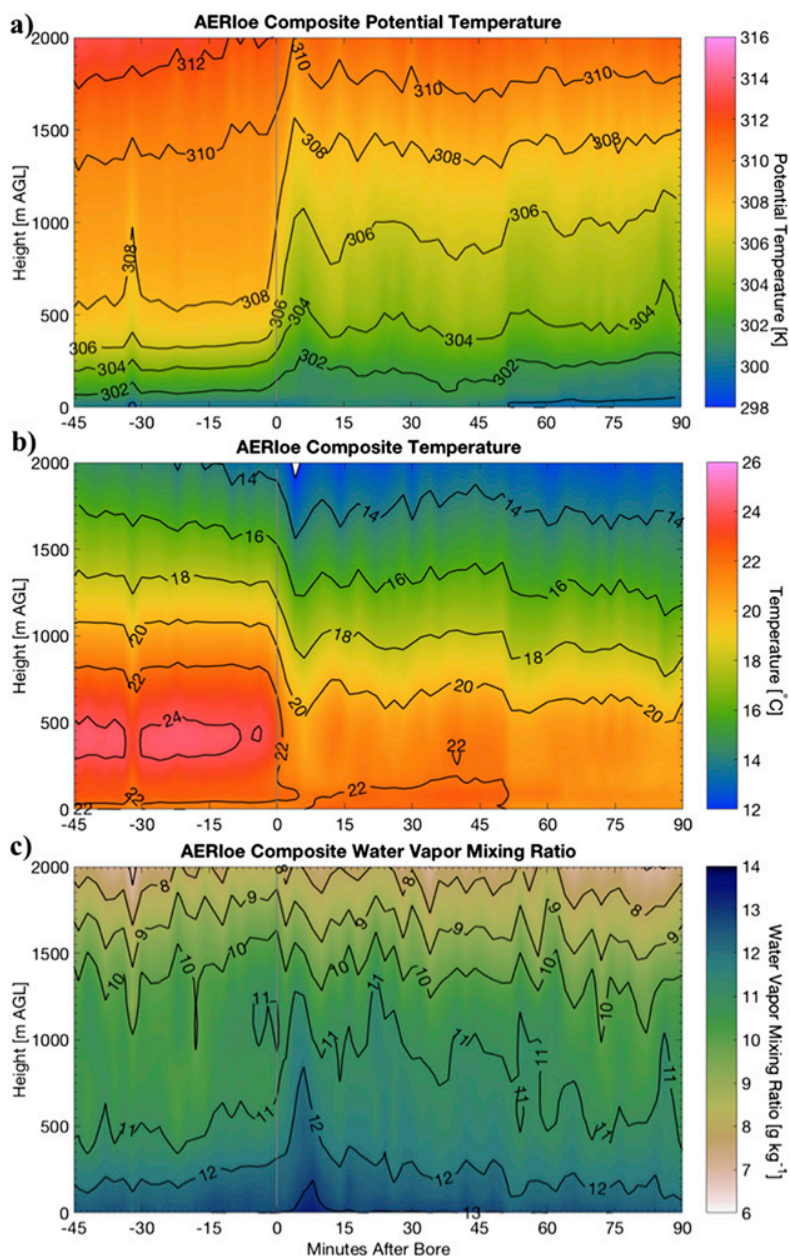

FIG. 3. Composite mean AERIoe retrievals of (a) potential temperature $(\mathrm{K})$ with isentropes labeled every $2 \mathrm{~K}$, (b) temperature $\left({ }^{\circ} \mathrm{C}\right)$ with isotherms labeled every $2^{\circ} \mathrm{C}$, and (c) water vapor mixing ratio $\left(\mathrm{g} \mathrm{kg}^{-1}\right)$ with isohumes labeled every $1 \mathrm{~g} \mathrm{~kg}^{-1}$.

The composite potential temperature time-height cross section, which was derived from AERIoe retrievals and shown in Fig. 3a, reveals abrupt lowlevel cooling of $2-3 \mathrm{~K}$ at the time of the bore with greatest cooling within the $250-1500 \mathrm{~m}$ above ground level (AGL) layer. Isentropic parcel displacements in the composite are as large as $900 \mathrm{~m}$, which is important when considering the potential for parcels to reach their level of free convection (LFC). The AERIoe composite temperature retrieval is shown in Fig. 3b. The temperature retrievals reveal an inversion with the maximum temperatures around $400 \mathrm{~m} \mathrm{AGL}, 3^{\circ} \mathrm{C}$ warmer than the surface. Low-level lifting (and thus the cooling) induced by the bore results in the reduction of static stability. As shown in Table 2, the inversion tends to be lifted to a greater height with the bore passage, which is different than the composite results. However, in two cases, the inversion manifests itself at a lower height following the
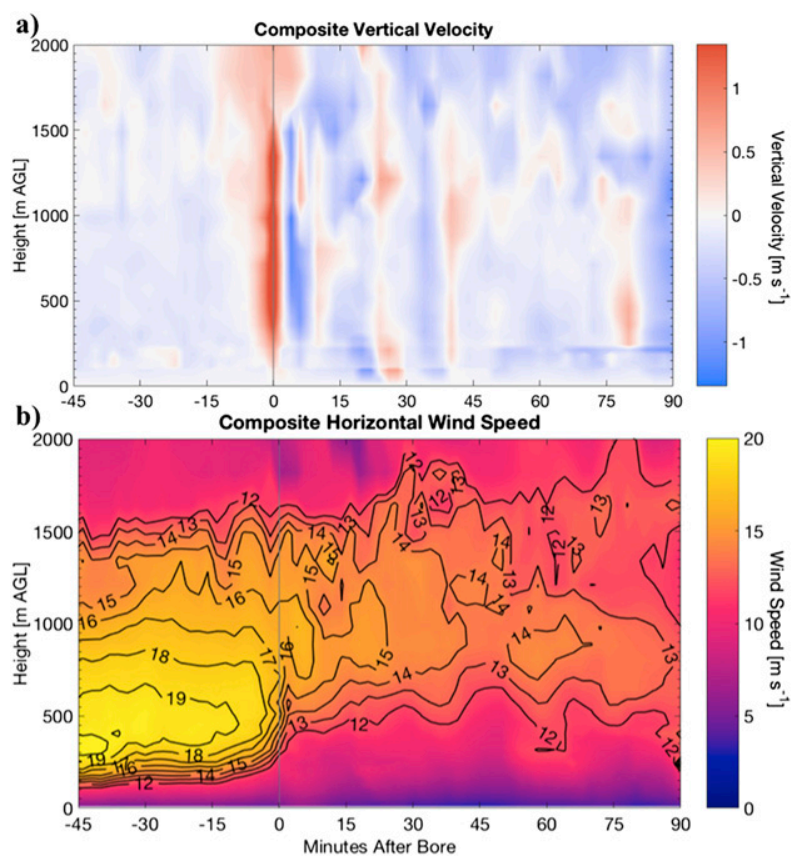

FIG. 4. Composite mean (a) vertical velocity $\left(\mathrm{m} \mathrm{s}^{-1}\right)$ and (b) horizontal wind speed $\left(\mathrm{m} \mathrm{s}^{-1}\right)$ with isotachs labeled from 12 to $20 \mathrm{~m} \mathrm{~s}^{-1}$.

bore, but in every case the inversion is weakened following the bore, as is shown in the composite. The composite does not indicate a lifting of the inversion however. Near-surface warming around $1^{\circ} \mathrm{C}$ corresponds well with composite surface temperature time series (Fig. 2b). The composite water vapor mixing ratio retrieval (Fig. 3c) indicates moistening from the surface up to about $1300 \mathrm{~m}$ AGL about $6 \mathrm{~min}$ after the bore, coinciding with the time of peak lifting in the potential temperature field with an increase around $1 \mathrm{~g} \mathrm{~kg}^{-1}$. This is despite the minimal change in water vapor mixing ratio observed in the surface observations, seen in Fig. 2c. Notably, the $11 \mathrm{~g} \mathrm{~kg}^{-1}$ isohume gets lifted from about $500 \mathrm{~m}$ AGL to an average of about $1000 \mathrm{~m}$ AGL with the bore passage. Between the cooling and moistening of the boundary layer, the bore increases the relative humidity of the boundary layer by $10 \%-15 \%$ (figure not shown). Despite the composite increase of $1 \mathrm{~g} \mathrm{~kg}^{-1}$ of water vapor, changes to composite precipitable water vapor were negligible (increase of $1 \mathrm{~mm}$ or approximately $5 \%$ of the prebore precipitable water vapor, figure not shown). Only one case exhibited a change in precipitable water vapor of greater $5 \mathrm{~mm}$ with the bore passage, the 20 June case at $\mathrm{FP} 4$, which resulted in a $30 \%(7 \mathrm{~mm})$ increase in precipitable water vapor.

The composite vertical velocity analysis from the radar wind profilers and Doppler lidars is shown in Fig. 4a. Vertical motions up to $1.5 \mathrm{~m} \mathrm{~s}^{-1}$, extending from $100 \mathrm{~m}$ 
AGL up to the level of reliable observations at $2000 \mathrm{~m}$ AGL, characterize bore passage as a series of easily identifiable updrafts coupled with less-coherent downdrafts. The strong initial updraft is followed approximately 10 min later by a weaker updraft with a maximum of $0.5 \mathrm{~m} \mathrm{~s}^{-1}$ that only extends from about 300 to $1400 \mathrm{~m}$ AGL. The next two updrafts revealed in the composite occur about 25 and $40 \mathrm{~min}$ after the bore. While the periodicity seems to change with time behind the bore in this composite, it is somewhat surprising that such coherent structures appear at all given that bores with different undulating periods would be expected to average each other out.

The horizontal wind speed analysis is shown in Fig. 3b. A LLJ peaking near $20 \mathrm{~m} \mathrm{~s}^{-1}$ can be identified in the prebore conditions in the composite at $500 \mathrm{~m}$ AGL. The LLJ has previously been identified as a typical wave trapping mechanism for bores (Crook 1988; Koch et al. 1991; Haghi et al. 2017; Toms et al. 2017), and was identified in the prebore environment in every case in which wind observations were available. The height and speed maximum of the LLJ in the pre- and postbore environments are shown in Table 2. In the composite, the LLJ gets lifted to about $1000 \mathrm{~m}$ AGL and weakens about $4 \mathrm{~m} \mathrm{~s}^{-1}$ with bore passage. The lifting and weakening is also a common feature in each case individually (Table 2). These changes to the low-level environment could promote low-level convergence and assist in initiating convection, provided the right orientation of the bore to the LLJ.

Using a water vapor differential absorption lidar (DIAL) at FP3, ceilometer at FP4, and the Doppler lidars on CLAMPS and SPARC, cloud base heights $(\mathrm{CBH})$ can be determined for each bore. Given a cloud base height, AERIoe derives cloud properties, including liquid water path (Turner and Löhnert 2014). These two quantities may be used to assess cloud development, and the composite time series of these two quantities is plotted in Fig. 5. CBH rapidly drops about $1600 \mathrm{~m}$ as the bore approaches, and has a minimum immediately after the bore passage. This suggests that the bore, in a composite sense, is forming a new low-level cloud. $\mathrm{CBH}$ has a small increase again about $10 \mathrm{~min}$ following the bore passage, shortly after the first downdraft following the bore. Two cases have clouds dissipate at this time ( $\mathrm{CBH}$ for the individual cases not shown) and return to a much higher background $\mathrm{CBH}$, which drives the increase in the composite $\mathrm{CBH}$. Composite liquid water path is observed to have a net increase of about $25 \mathrm{~g} \mathrm{~m}^{-2}$ with the bore passage. This indicates that the clouds are thickening with the bore passage.

It is possible to calculate a time series of convective indices from the AERIoe retrievals in order to identify

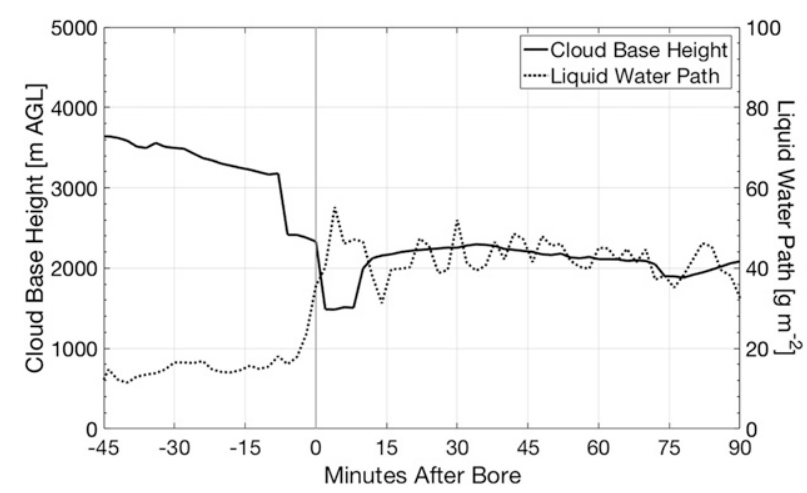

FIG. 5. Composite mean time series of cloud-base height (solid line, left axis, m AGL), as measured by a water vapor differential absorption lidar (DIAL) at FP3, ceilometer at FP4, and Doppler lidars on CLAMPS and SPARC, and liquid water path (dotted line, right axis, $\mathrm{g} \mathrm{m}^{-2}$ ) retrieved by AERIoe.

trends in atmospheric stability. As with the finding from Blumberg et al. (2017a), the most valuable information from AERI-derived convective indices are the trends identified in the time series as opposed to the absolute magnitudes. AERI-derived thermodynamic retrievals have been used to monitor stability trends in convective environments (Feltz and Mecikalski 2002; Feltz et al. 2003; Wagner et al. 2008). The Sounding/Hodograph Analysis and Research Program in Python (SHARPpy; Blumberg et al. 2017b) was used to calculate convective indices from the AERIoe retrievals. These indices were calculated for the $100-\mathrm{hPa}$ mixed layer (following the finding of Blumberg et al. 2017a) for each individual case and then averaged together in order to form the composite time series. Convective indices calculated from the mean temperature and water vapor profiles were also considered and compared to this method, but as both revealed similar trends, they are not presented here. We decided not to include the most-unstable parcel calculated indices given that they displayed similar trends to the mixed-layer calculations, and the most-unstable layer was never observed to change with the bore passage. We believe this is a product of the limited vertical resolution of the AERIoe retrievals.

The composite time series of mixed-layer convective available potential energy (MLCAPE) and convective inhibition (MLCIN) are shown in Fig. 6a. MLCAPE rapidly increases about $200 \mathrm{~J} \mathrm{~kg}^{-1}$ with the bore passage, and takes about $60 \mathrm{~min}$ to gradually return to prebore values. This increase is due to the increase in water vapor in the near-surface layer following the bore (Fig. 3c). MLCIN has a rapid decrease of $225 \mathrm{~J} \mathrm{~kg}^{-1}$ within the first $4 \mathrm{~min}$ of the bore passage. MLCIN increases again after that and levels off, with a net decrease of about 

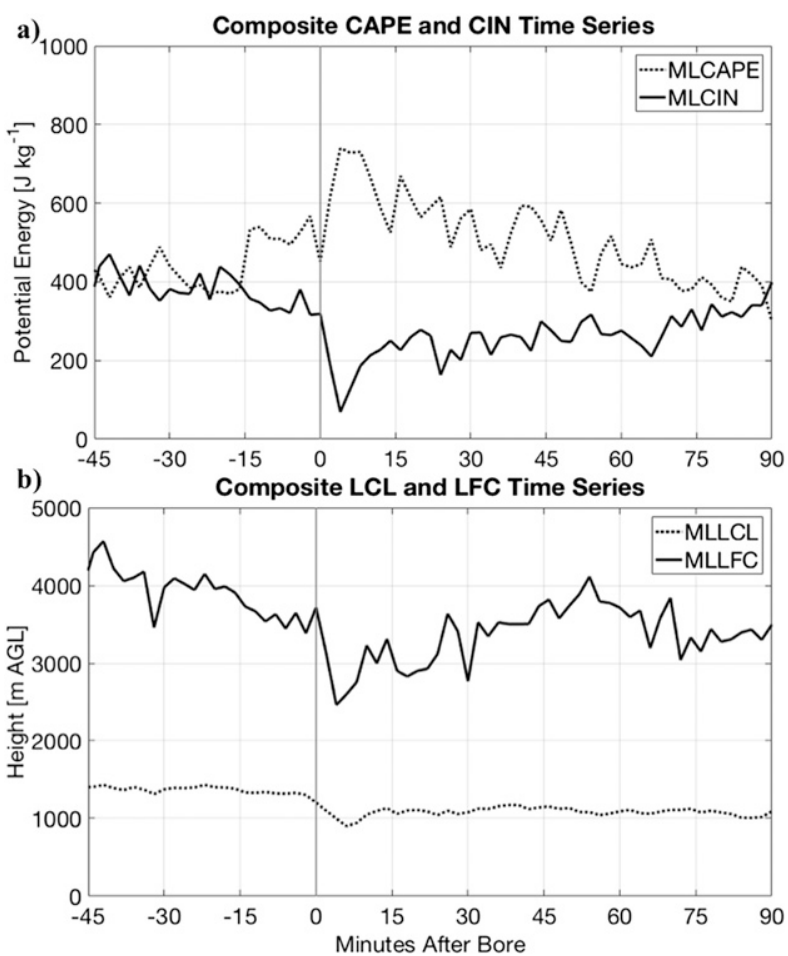

FIG. 6. Composite mean time series of (a) 100-hPa mixed-layer (ML) CAPE $\left(\mathrm{J} \mathrm{kg}^{-1}\right.$, dotted line) and CIN $\left(\mathrm{J} \mathrm{kg}^{-1}\right.$, solid line) and (b) ML LCL height (m AGL, dotted line) and LFC height (m AGL, solid line).

$150 \mathrm{~J} \mathrm{~kg}^{-1}$ compared to the prebore environment for about an hour. The weakening of the capping inversion and decrease in CIN has also been documented previously (e.g., Koch et al. 1991, 2008; Coleman and Knupp 2011). Figure 6b displays time series of ML calculated lifted condensation level (LCL) and level of free convection (LFC). Both MLLCL and MLLFC decrease with the bore passage, with the MLLCL height lowering $300 \mathrm{~m}$ and the MLLFC height decreasing by almost $1000 \mathrm{~m}$. Both of these decreases would also be a result of the increase in water vapor near the surface following the bore passage. MLLFC returns to similar values as the prebore environment about $45 \mathrm{~min}$ after the bore. However, MLLCL stays roughly $300 \mathrm{~m}$ lower compared to the prebore environment throughout the time series displayed. The composite MLLCL (Fig. 6b) stays $400 \mathrm{~m}$ lower than the minimum in composite CBH (Fig. 5), suggesting the lifted parcels resulting in cloud formation are originating above the $100-\mathrm{hPa}$-deep mixed layer.

In summary, previous studies of single events have shown that bores reduce the static stability of the atmosphere (Koch et al. 1991, 2008; Coleman and Knupp 2011; Parsons et al. 2019). The trends identified in this composite confirm that result across a set of eight bores in various stages of their life cycle. In the composite presented here, the reduction in static stability is done through increases in near-surface water vapor and breaking down of the capping inversion through low-level lifting, which has been discussed previously as well (e.g., Koch et al. 2008; Coleman and Knupp 2011; Parsons et al. 2019). Overall, a conclusion similar conclusion to Coleman and Knupp (2011) can be drawn: bores make convective initiation in the postbore environment more likely as compared to the prebore environment.

\section{b. Wavenumber composite}

By compositing in time, it is likely that undulating features are averaged out due to differences in periodicity in each case. Using vertical velocity observations for each of the six cases for which wind data are available, we are able to identify a wave period, defined as the time between the initial updraft (at the onset of the bore) and the next updraft (the onset of the following wave). This allows us to composite the bores on a wave-space grid, which can account for the different periodicities in each case. Those periodicities for each case are shown in Table 2 and Fig. 7, which displays the vertical velocities for each case on a similar wavenumber grid. It is first worth noting how different each bore may be from another in its kinematic field. Several examples of note: the case on 2 June at FP3 (Fig. 7b) has a stronger updraft following the bore than at the bore front; the 7 June case at FP3 (Fig. 7c) appears to have a tilted updraft in the leading edge of the first wave behind the bore front; and the 20 June case at FP4 (Fig. 7d) appears to have two separate vertical velocity maxima associated with the leading wave behind the bore front. Several studies have documented observations of bores with a stronger updraft following the bore front (Hartung et al. 2010; Mueller et al. 2017; Toms et al. 2017).

The wave-space composites for vertical velocity and horizontal wind speed are displayed in Fig. 8. The vertical velocity composite, displayed in Fig. 8a, shows welldefined updrafts at wavenumber 0 (start of the bore), and wavenumbers 1,3 , and 5 . There is some evidence of an updraft at wavenumber 4 , given slightly positive values in the lowest $700 \mathrm{~m}$, but there is a complete absence of an updraft at wavenumber 2 .

The reason for the absence of an updraft at wavenumber 2 requires further investigation. Overall, it appears that the periods of the bores change, from the perspective of the observing platforms. Recall that the periodicity is determined based on the updraft at the onset of the bore and the updraft at the first trailing wave. This method can be seen in each case in Fig. 7, 

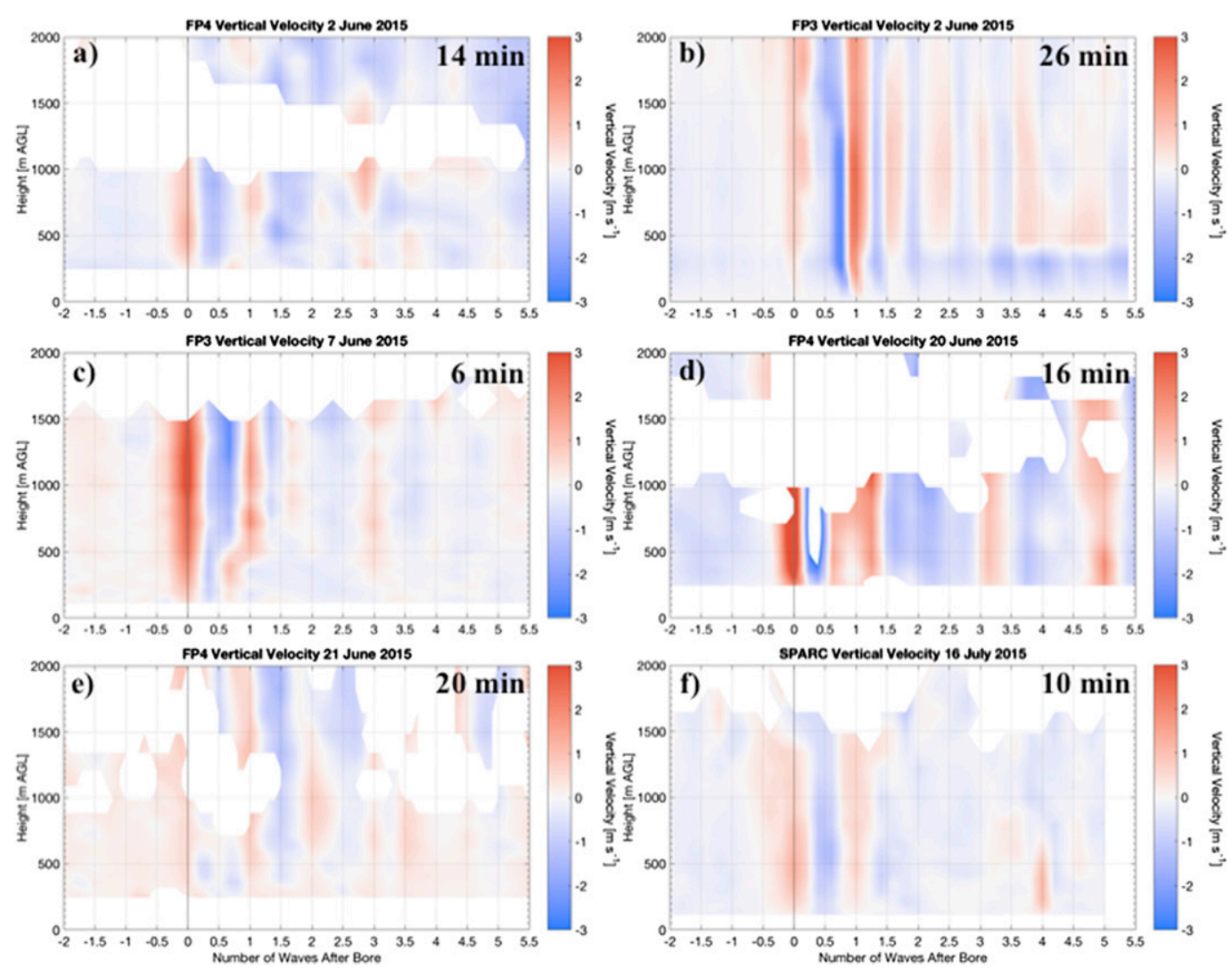

FIG. 7. Vertical velocity observations for each case displayed on the wavenumber axis. Periodicities for each case are displayed as a reference.

where the first updraft is centered at wavenumber zero and the following updraft is centered at wavenumber 1 . However, after wavenumber 1 , the updrafts do not align with our expected wavenumber axis, thus we reach the conclusion that the periodicity (as observed at the point locations of these observations) is changing. This could be related to the bore changing propagation speed (as has previously been shown to happen in Knupp 2006) or changes in the environment (such as stability or wind shear) that are causing the bore to change its oscillating frequency. Furthermore, the different time resolutions between wind profilers ( 5 min for $449-\mathrm{MHz}$ wind profiler at FP3, 10 min with 5-min update cycle for $915-\mathrm{MHz}$ wind profiler at FP4, 2 min for Doppler lidars at FP3, CLAMPS, and SPARC) allows for the potential of having periodicities misrepresented due to the sampling resolution which could also contribute to this observed behavior. Additional research is needed in order to fully explain changing bore propagation speeds and periodicities.

The wave-based composite of horizontal wind speed (Fig. 8b) is very similar to the time-based composite in Fig. 4b. The isotachs in the postbore environment display oscillations, and the LLJ is still observed to weaken behind the bore. Overall, the major features are still very similar between the wave-space and the time composites of horizontal wind speed.

The wave-space composite for the surface variables, displayed in the time-based composite in Fig. 2, is displayed in Fig. 9. There is slightly greater oscillation seen in the composite surface pressure field in the wave-space composite (Fig. 9a) compared to the time composite (Fig. 2a). However, with only three cases displaying oscillations in the pressure field (only one case displays prolonged oscillations), it is not surprising that the composite mean displays only a weak oscillation through the first wave following the bore. Additionally, the pressure field appears to lag by about 0.3 waves compared to the vertical velocity field. Furthermore, neither the surface temperature (Fig. 9b) nor the surface water vapor mixing ratio (Fig. 9c) revealed any new features compared to the time composite.

The wave-space composites of the AERIoe retrievals are displayed in Fig. 10. Beginning with potential temperature in Fig. 10a, the oscillating nature of the isentropic field is similar to what would be expected given the vertical velocity field in Fig. 8a. This is especially 


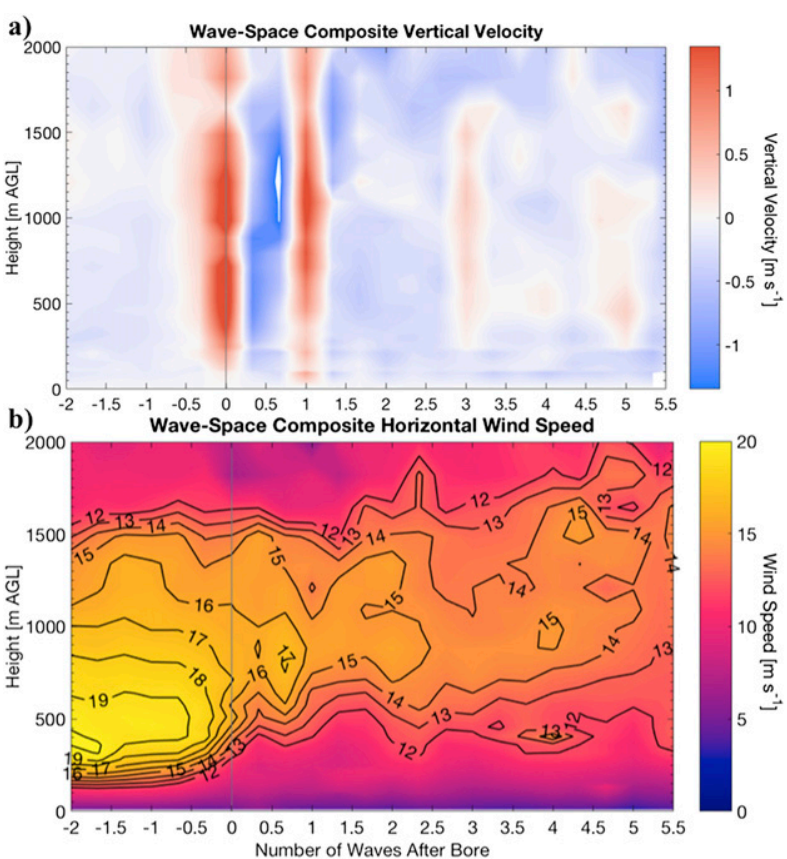

FIG. 8. As in Fig. 4, but on a wavenumber axis instead of time.

evident with the 306-K isentrope, which like the vertical velocity field, oscillates through wavenumber 5 , but does not display an oscillation at wavenumber 2 . The oscillations in the isentropic field lag almost 0.5 waves compared to the vertical velocity field, similar to what was seen in the surface pressure composite in Fig. 9a. The oscillations have only a $1-\mathrm{K}$ difference between each phase; therefore, this result suggests changes to the environment are minimal with the undulations compared to the bore front. The wave-space composite of temperature (Fig. 10b) reveals similar results to the time composite, with cooling of the entire profile occurring with the bore front. Weak warming of about $1^{\circ} \mathrm{C}$ occurs with the leading downdraft immediately behind the bore front. However, the low-level inversion never redevelops in the downward motion/ warming phase of the undulations. Water vapor lofting immediately following the bore is observed in the wave-space composite of water vapor mixing ratio, shown in Fig. 10c. This was also shown in the time composite in Fig. 3c. However, the oscillation in the $11 \mathrm{~g} \mathrm{~kg}^{-1}$ isohume (seen in both the time composite in Fig. $3 c$ and the wave-space composite in Fig. 10c) is related to the kinematic oscillations of the bore (seen in Fig. 8a), albeit with slightly different lag times compared to the updrafts. This second updraft following the bore (wavenumber 1) seems to be able to induce mixing in the 500-1000-m AGL layer, given the lifting of the $11 \mathrm{~g} \mathrm{~kg}^{-1}$ isohume between wavenumber 1.5 and 2 , but not at the surface, as the $12 \mathrm{~g} \mathrm{~kg}^{-1}$ isohume drops about $100 \mathrm{~m}$.
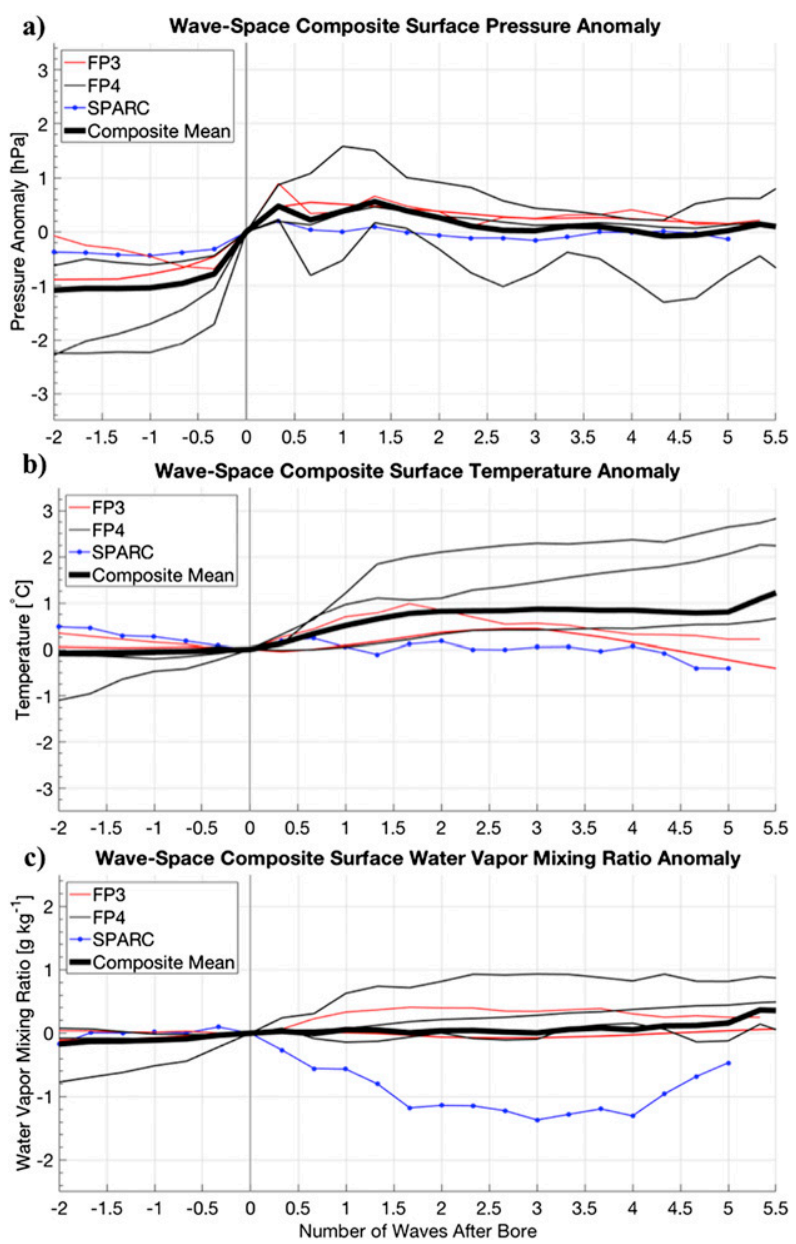

FIG. 9. As in Fig. 2, but on a wavenumber axis instead of time.

The wave-space composites of $\mathrm{CBH}$ and liquid water path are displayed in Fig. 11. The CBH rapidly decreases with the bore front, as was also shown in Fig. 5, but then increases following the occurrence of the second downdraft at wavenumber 1.5. In this composite mean, the cloud formed by the bore persists through the first downdraft at wavenumber 0.5 , and diminishes with the second downdraft at wavenumber 1.5. The liquid water path oscillates with a 0.5 wavenumber lag to the vertical velocity in the composite (Fig. 8a), similar to the behavior of other variables discussed above (and shown in Figs. 9a and 10a). This behavior in liquid water path suggests an initial development and thickening of the cloud associated with the bore front, followed by a thinning of that cloud with the first downdraft. The cloud thickens again with the following updraft, but then the $\mathrm{CBH}$ rises with the rising liquid water path. As was noted earlier, two cases have clouds that dissipate at this time and the $\mathrm{CBH}$ returns to a much higher background $\mathrm{CBH}$ and drives the increase in the composite $\mathrm{CBH}$ at that time. Only one case displayed oscillations 

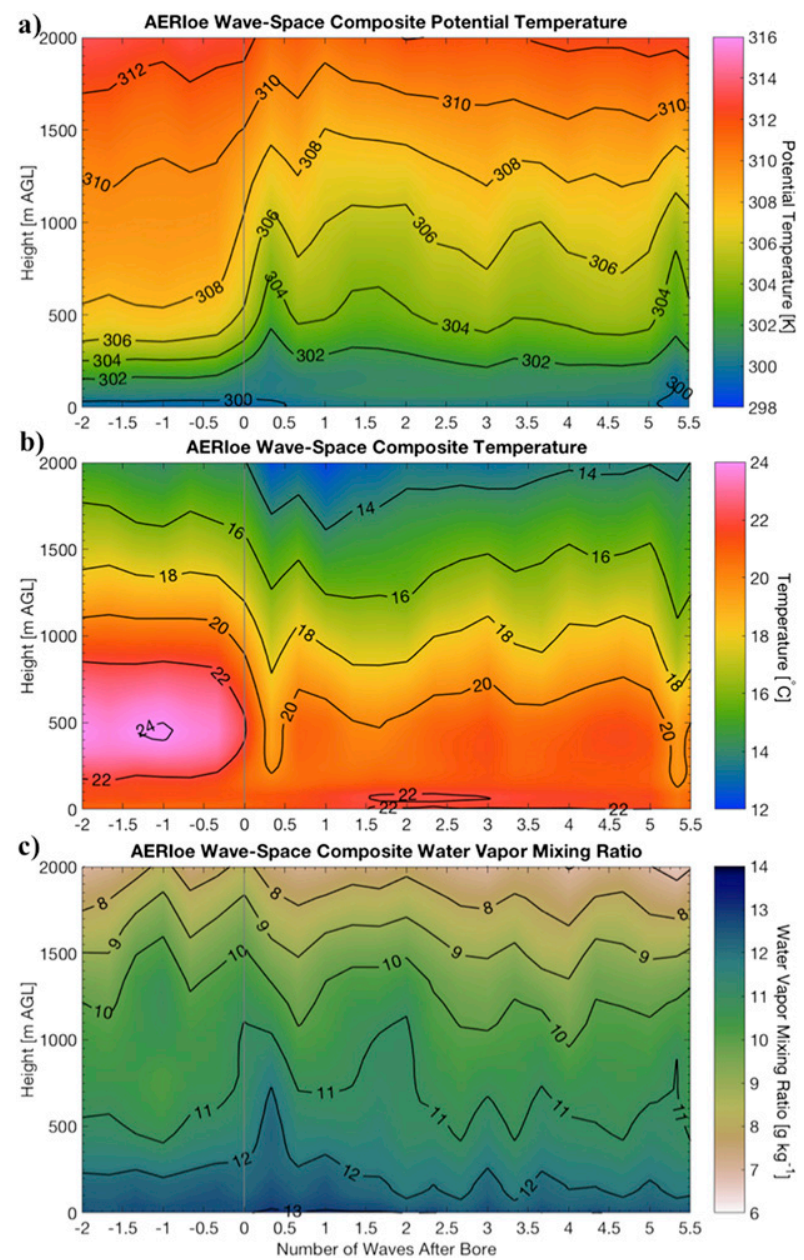

FIG. 10. As in Fig. 3, but on a wavenumber axis instead of time.

in liquid water path beyond wavenumber 2 . This case had a local maximum at wavenumber 3 and wavenumber 5 , which is responsible for the corresponding local maxima at those times in the composite.

Wave-space composites of convective indices are displayed in Fig. 12. As was just seen in Fig. 10, thermodynamic changes with each oscillation are fairly small $\left(1^{\circ} \mathrm{C}\right.$ and $\left.1 \mathrm{~g} \mathrm{~kg}^{-1}\right)$, so it is not surprising that the convective indices do not have a clear undulation pattern behind the bore. MLCAPE (Fig. 12a) and MLLFC (Fig. 12b) have a weak oscillation between wavenumber 0 and wavenumber 1 (besides the larger change induced by the bore front) but it is not a large enough change to be confident it is induced by the bore and not just noise. However, given the weak changes to the thermodynamics, small oscillations to convective indices should still be expected. Aside from the case of MLLCL, which has very minimal change, the convective indices displayed suggest that changes to atmospheric stability induced by the bore would only persist through the first

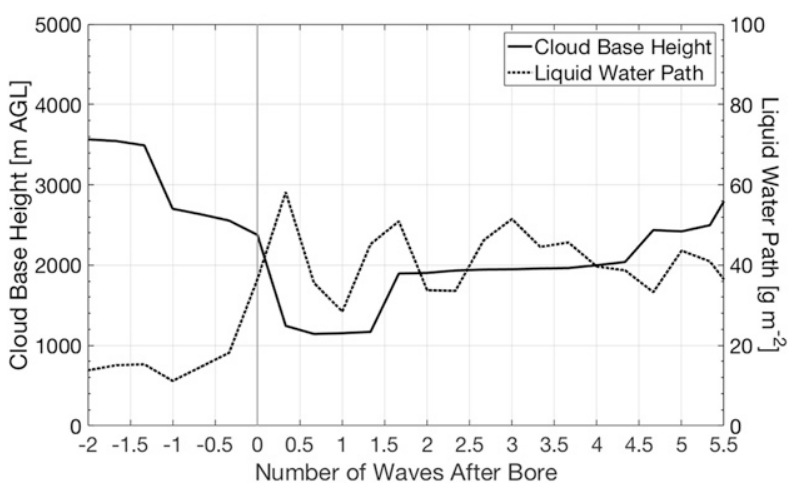

FIG. 11. As in Fig. 5, but on a wavenumber axis instead of time.

two wave cycles. Beyond wavenumber 2, MLCAPE and MLLFC have returned to similar levels as in the prebore environment, while MLCIN remains at slightly decreased levels compared to the prebore environment.

Overall, the wave-space composite has shown some of the oscillatory nature of bores. However, changing periodicities or sampling frequencies that are too long result in the composite struggling with the later oscillatory features behind the bore front. In this wavespace composite, undulations in the thermodynamic field are minimal, and do not have large impacts on the trends of convective indices; the strongest effect by far is caused by the bore front alone.

\section{c. Bore variability}

Comparisons between the prebore and postbore environment were also analyzed for each case to gain a greater sense of the variability of changes caused by bore passages, something that the composite alone cannot display. To do this comparison, we average each variable in the range of 6-30-min pre- and postbore passage, thus avoiding the turbulent environment around the time of the bore. We take differences such that a positive value indicates that the particular variable increased with the bore passage.

Figure 13a displays the changes to 300 and $1000 \mathrm{~m}$ AGL temperature and water vapor mixing ratio. At both 300 and $1000 \mathrm{~m}$ AGL temperature decreases are primarily around $2^{\circ}-3^{\circ} \mathrm{C}$ with the strongest cases showing cooling near $5^{\circ} \mathrm{C}$. Both 300 and $1000 \mathrm{~m}$ AGL water vapor mixing ratio changes display more variation, with some cases resulting in drying at low levels, opposite of what was shown in the composite. The median values are similar to the moistening trend seen in the composite (Fig. 3c). Bores can have much greater moistening than shown in the composite, with the greatest case having an increase of more than $3 \mathrm{~g} \mathrm{~kg}^{-1}$ at $1000 \mathrm{~m}$.

Changes to convective indices are shown in Fig. 13b. Across the averaging period, MLCAPE had either 

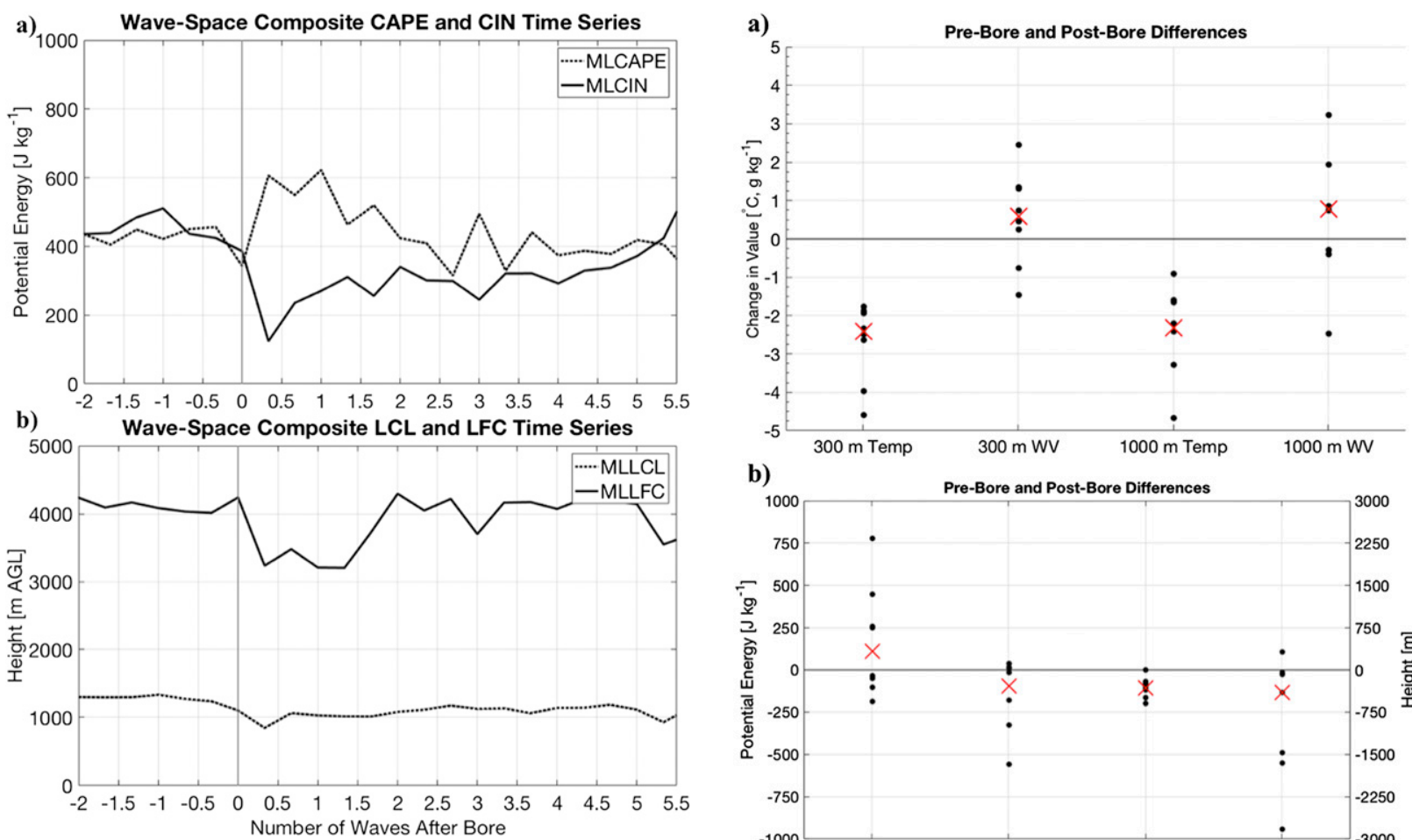

b)

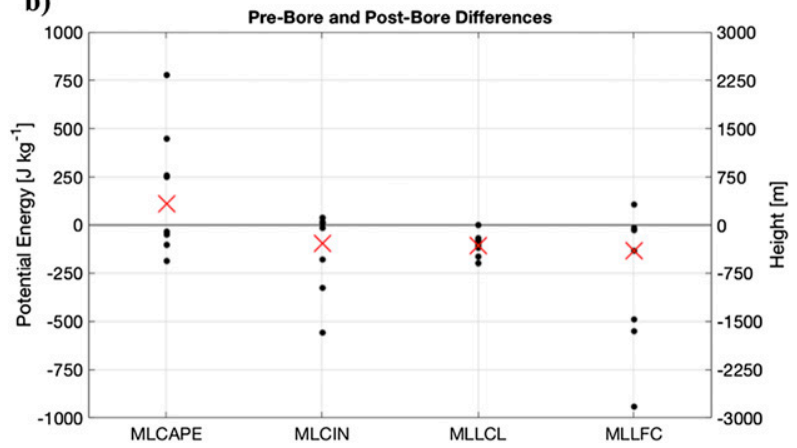

FIG. 12. As in Fig. 6, but on a wavenumber axis instead of time.

large increases or small decreases. All the cases that increased in MLCAPE had gains of $250 \mathrm{~J} \mathrm{~kg}^{-1}$ or more, while the cases that had decreases did not decrease by more than $200 \mathrm{~J} \mathrm{~kg}^{-1}$. Similar behavior is shown in the changes to MLCIN, as many cases had nearly zero change, but three cases resulted in large decreases in MLCIN. In every case, MLLCL decreased, though never by more than $250 \mathrm{~m}$. In addition, all but one case resulted in lowered MLLFC heights with the bore passage. In general, it appears bores make convective initiation more likely, but only some bores change the environment in ways that may allow for stronger convection.

We can also look at the relation between thermodynamic changes and the changes on the convective indices. Figure 14a displays scatterplots relating changes in $300 \mathrm{~m} \mathrm{AGL}$ water vapor mixing ratio to changes in MLCAPE, while Fig. 14b shows how changes in $300 \mathrm{~m}$ AGL temperature impact changes in MLCIN. Each case in Fig. 14 is colored according to its prebore average of the respective convective index to provide a reference for the relative magnitude of the change. The changes in MLCAPE are well explained by changes to low-level water vapor mixing ratio, as was suggested earlier in the composite analysis. These bores that result in increased low-level water vapor would be of greatest interest because they allow for

FIG. 13. Prebore and postbore differences for (a) 300- and 1000-m temperature $\left({ }^{\circ} \mathrm{C}\right)$ and 300 - and $1000-\mathrm{m}$ water vapor mixing ratio ( $\mathrm{g} \mathrm{kg}^{-1}$ ), and (b) 100-hPa mixed-layer (ML) CAPE and CIN (left axis, $\mathrm{J} \mathrm{kg}^{-1}$ ) and MLLCL and MLLFC height (right axis, $\mathrm{m}$ ). Changes are calculated as the difference between average of the respected variable 6-30 min before and after the time of the bore, such that a positive value is an increase in the variable with the bore passage. Red " $X$ " is the median change for each variable.

stronger convection in the postbore environment. MLCAPE had little relation to changes in $300 \mathrm{~m}$ AGL temperature (not shown). However, MLCIN appears to be more closely related to changes in $300 \mathrm{~m}$ AGL temperature (Fig. 14b), and did not have any relation to water vapor mixing ratio changes (not shown). This implies that the mechanism for decreased MLCIN in the composite is mechanical lifting by the bore resulting in cooling and breaking down of the near-surface capping inversion.

\section{Conclusions}

This study has created a composite analysis of the thermodynamic and kinematic state of the atmosphere for eight separate atmospheric bore cases during the PECAN campaign using high-temporal-resolution profiling instruments. While many more bore-like gravity waves were observed during the campaign, they were either too close to the parent density current to be identified as a bore using our defining criteria or too 


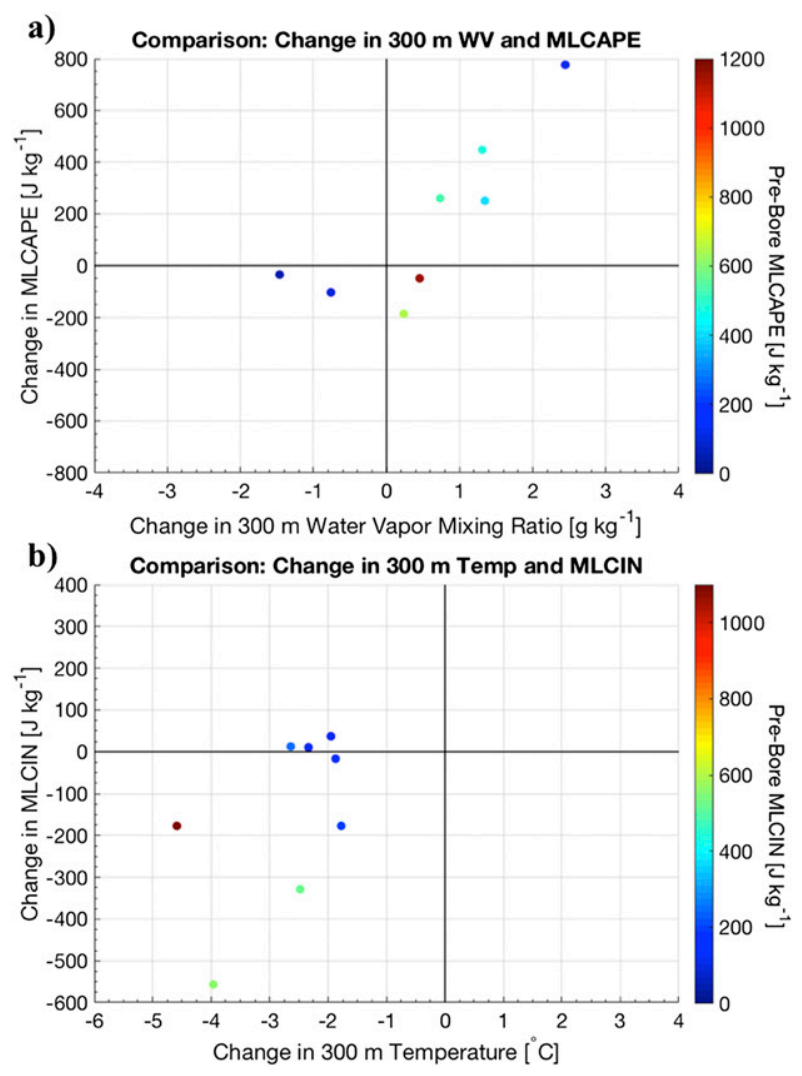

FIG. 14. Scatterplots displaying (a) the change in 300-m water vapor mixing ratio ( $x$ axis, $\mathrm{g} \mathrm{kg}^{-1}$ ) compared to the change in MLCAPE ( $y$ axis, $\mathrm{J} \mathrm{kg}^{-1}$ ), and (b) the change in 300-m temperature $\left(x\right.$ axis, $\left.{ }^{\circ} \mathrm{C}\right)$ compared to the change in MLCIN ( $y$ axis, $\left.\mathrm{J} \mathrm{kg}^{-1}\right)$. Changes are calculated the same as in Fig. 10. Dots are colored according to the (a) prebore MLCAPE average and (b) prebore MLCIN average.

close to precipitation to allow for AERI observations. This study combines multiple bores with uniform thermodynamic profiling instrumentation within a single methodology. This analysis has focused on documenting typical changes to boundary layer temperature and water vapor structure with a particular focus on stability trends with bore passages in order to better understand how the boundary layer evolves during bore passages and how that can impact convective initiation. Previous observational studies have primarily focused on one or two bores in the context of a case study. Recently, Haghi et al. (2017) and Parsons et al. (2019) analyzed larger datasets of bores, but they did not document boundary layer and stability trends as has been done here.

The key findings of this study can be summarized as follows:

- Composite mean time series of convective indices identified reductions in MLCIN and MLLFC height, along with increases in MLCAPE with the bore passage, which would favor future convective initiation behind the bore.

- Changes in $300 \mathrm{~m}$ AGL water vapor mixing ratio were found to be important for explaining changes in MLCAPE with bore passages, with increases in water vapor tending to increase MLCAPE.

- Changes in $300 \mathrm{~m}$ AGL temperature were found to be the best explanation for changes to MLCIN, with greater cooling resulting in greater decreases in MLCIN.

- The bore front produces the greatest effects changing the boundary layer and thus static stability, compared to the changes induced by the trailing undulations.

Coleman and Knupp (2011) analyzed high-temporalresolution time series of convective indices for a single case, similar to what has been presented here across a number of cases. This study has found bores to decrease CIN and LFC height in many instances, which would increase the potential for convective initiation, adding further evidence to the conclusion of Coleman and Knupp (2011). Comparisons of prebore to postbore profiles in numerous studies (e.g., Koch et al. 2008; Grasmick et al. 2018; Parsons et al. 2019) have also drawn similar conclusions. The maximum vertical parcel displacement shown in the composite was approximately $900 \mathrm{~m}$ (similar to Parsons et al. 2019). While that may not be enough to lift parcels to their LFC, the bore's modification of the LFC height may allow a trailing boundary (such as the parent density current) to provide enough lift to initiate convection, as previously shown in cases documented by Koch and Clark (1999) and Blake et al. (2017).

These results have important implications that can be applied to real-time forecasting of potential convective initiation. Operational forecasters are able to identify the presence of a bore using surface and radar observations, and may be able to infer water vapor trends based on changes to the surface water vapor concentration. However, knowledge of the parcel displacements aloft is difficult to determine using those information sources. Synthesizing typical parcel displacements identified in this study and information on the environmental LFC height can provide clues as to the potential for the bore initiating convection.

It seems that the most interest would be in the cases that resulted in moistening of the boundary layer, which tends to increase CAPE - a combination that would increase both the probability of convective initiation and the intensity of the convection that develops. Given the variability displayed in this study, the question remains whether or not there are characteristics of the environment that allows bores to have greater mechanical lifting 
(more cooling, greater decrease in MLCIN). Additionally, identifying the conditions that allow for greater water vapor lofting in bores, and what the source of that water vapor is, remains an unanswered question. The work by Koch et al. (2008), identifying active and dissipation phases of the bore and suggesting a relation between turbulent mixing and life cycle of the bore, may serve as a guide to this problem. If characteristics of the environment that the bore is propagating into are able to provide clues to the water vapor lofting tendencies the bore will have, then there would be the potential to predict that a particular bore will make its environment more favorable for both initiating and sustaining stronger convection.

Acknowledgments. The authors wish to thank the PECAN teams for collecting these data, and the ARM program for providing the AERIs for the fixed profiling locations during the field campaign. The authors also wish to thank William Brown of NCAR for providing the $449-\mathrm{MHz}$ and $915-\mathrm{MHz}$ wind profiler data at FP3 and FP4 at higher temporal resolution. This research is supported by National Science Foundation (NSF) Grant 1359614 "Collaborative Research: Low-level Jets in the Nocturnal Stable Boundary Layer: Structure, Evolution, and Interactions with Mesoscale Atmospheric Disturbances" and by the NOAA Atmospheric Science for Renewable Energy (ASRE) program. The authors also wish to thank Kevin Haghi for his comments throughout this study, and two anonymous reviewers for their comments and insight, which greatly enhanced the quality of this manuscript.

\section{REFERENCES}

Benjamin, S. G., and Coauthors, 2016: A North American hourly assimilation and model forecast cycle: The Rapid Refresh. Mon. Wea. Rev., 144, 1669-1694, https://doi.org/10.1175/ MWR-D-15-0242.1.

Blake, B. T., D. B. Parsons, K. R. Haghi, and S. G. Castleberry, 2017: The structure, evolution, and dynamics of a nocturnal convective system simulated using the WRF-ARW model. Mon. Wea. Rev., 145, 3179-3201, https://doi.org/10.1175/MWR-D-16-0360.1.

Blumberg, W. G., T. J. Wagner, D. D. Turner, and J. Correia Jr., 2017a: Quantifying the accuracy and uncertainty of diurnal thermodynamic profiles and convection indices derived from the Atmospheric Emitted Radiance Interferometer. J. Appl. Meteor. Climatol., 56, 2747-2766, https://doi.org/ 10.1175/JAMC-D-17-0036.1.

—_, K. T. Halbert, T. A. Supinie, P. T. Marsh, R. L. Thompson, and J. A. Hart, 2017b: SHARPpy: An open source sounding analysis toolkit for the atmospheric sciences. Bull. Amer. Meteor. Soc., 98, 1625-1636, https://doi.org/10.1175/BAMSD-15-00309.1.

Christie, D. R., 1989: Long nonlinear waves in the lower atmosphere. J. Atmos. Sci., 46, 1462-1491, https://doi.org/10.1175/ 1520-0469(1989)046<1462:LNWITL>2.0.CO;2.
— K. J. Muirhead, and A. L. Hales, 1978: On solitary waves in the atmosphere. J. Atmos. Sci., 35, 805-825, https://doi.org/ 10.1175/1520-0469(1978)035<0805:OSWITA $>2.0$.CO;2.

Clarke, R. H., R. K. Smith, and D. G. Reid, 1981: The Morning Glory of the Gulf of Carpentaria: An atmospheric undular bore. Mon. Wea. Rev., 109, 1726-1750, https://doi.org/10.1175/ 1520-0493(1981)109<1726:TMGOTG > 2.0.CO;2.

Coleman, T. A., and K. R. Knupp, 2011: Radiometer and profiler analysis of the effects of a bore and a solitary wave on the stability of the nocturnal boundary layer. Mon. Wea. Rev., 139, 211-223, https://doi.org/10.1175/2010MWR3376.1.

— - — , and D. E. Herzmann, 2010: An undular bore and gravity waves illustrated by dramatic time-lapse photography. J. Atmos. Oceanic Technol., 27, 1355-1361, https://doi.org/ 10.1175/2010JTECHA1472.1.

Colman, B. R., 1990: Thunderstorms above frontal surfaces in environments without positive CAPE. Part I: A climatology. Mon. Wea. Rev., 118, 1103-1121, https://doi.org/10.1175/ 1520-0493(1990)118<1103:TAFSIE $>2.0$. CO;2.

Crook, N. A., 1988: Trapping of low-level internal gravity waves. J. Atmos. Sci., 45, 1533-1541, https://doi.org/10.1175/ 1520-0469(1988)045<1533:TOLLIG > 2.0.CO;2.

Ecklund, W. L., D. A. Carter, B. B. Balsley, P. E. Currier, J. L. Green, B. L. Weber, and K. S. Gage, 1990: Field tests of a lower tropospheric wind profiler. Radio Sci., 25, 899-906, https://doi.org/10.1029/RS025i005p00899.

Feltz, W. F., and J. R. Mecikalski, 2002: Monitoring hightemporal resolution convective stability indices using the ground-based Atmospheric Emitted Radiance Interferometer (AERI) during the 3 May 1999 Oklahoma-Kansas tornado outbreak. Wea. Forecasting, 17, 445-455, https://doi.org/10.1175/ 1520-0434(2002)017<0445:MHTRCS >2.0.CO;2.

, W. L. Smith, H. B. Howell, R. O. Knuteson, H. Woolf, and H. E. Revercomb, 2003: Near-continuous profiling of temperature, moisture, and atmospheric stability using the Atmospheric Emitted Radiance Interferometer (AERI). J. Appl. Meteor., 42, 584-597, https://doi.org/10.1175/1520-0450(2003)042<0584: NPOTMA $>2.0 . \mathrm{CO} ; 2$.

French, A. J., and M. D. Parker, 2010: The response of simulated nocturnal convective systems to a developing lowlevel jet. J. Atmos. Sci., 67, 3384-3408, https://doi.org/ 10.1175/2010JAS3329.1.

Fritsch, J. M., R. J. Kane, and C. R. Chelius, 1986: The contribution of mesoscale convective weather systems to the warm-season precipitation in the United States. J. Climate Appl. Meteor., 25, 1333-1345, https://doi.org/10.1175/1520-0450(1986)025<1333: TCOMCW $>2.0 . \mathrm{CO} ; 2$.

Geerts, B., and Q. Miao, 2005: The use of millimeter Doppler radar echoes to estimate vertical air velocities in the fair-weather convective boundary layer. J. Atmos. Oceanic Technol., 22, 225-246, https://doi.org/10.1175/JTECH1699.1.

_ , and Coauthors, 2017: The 2015 Plains Elevated Convection At Night field project. Bull. Amer. Meteor. Soc., 98, 767-786, https://doi.org/10.1175/BAMS-D-15-00257.1.

Grasmick, C., B. Geerts, D. D. Turner, T. M. Weckwerth, and Z. Wang, 2018: The relation between nocturnal MCS evolution and its outflow boundaries in the stable boundary layer: An observational study of the 15 July 2015 MCS in PECAN. Mon. Wea. Rev., 146, 3203-3226, https://doi.org/10.1175/MWR-D-18-0169.1.

Haghi, K. R., D. B. Parsons, and A. Shapiro, 2017: Bores observed during IHOP_2002: The relationship of bores to the nocturnal environment. Mon. Wea. Rev., 145, 3929-3946, https://doi.org/ 10.1175/MWR-D-16-0415.1. 
Hanesiak, J., and D. D. Turner, 2016: FP3 University of Manitoba Doppler Lidar wind profile data (version 1.0). UCAR/NCAR Earth Observing Laboratory, accessed 14 March 2018, https:// doi.org/10.5065/D60863P5.

Hartung, D. C., J. A. Otkin, J. E. Martin, and D. D. Turner, 2010: The life cycle of an undular bore and its interaction with a shallow, intense cold front. Mon. Wea. Rev., 138, 886-908, https://doi.org/10.1175/2009MWR3028.1.

Heideman, K. F., and J. M. Fritsch, 1988: Forcing mechanism and other characteristics of significant summertime precipitation. Wea. Forecasting, 3, 115-130, https://doi.org/10.1175/ 1520-0434(1988)003<0115:FMAOCO > 2.0.CO;2.

Johnson, A., X. Wang, K. R. Haghi, and D. B. Parsons, 2018: Evaluation of forecasts of a convectively generated bore using an intensively observed case study from PECAN. Mon. Wea. Rev., 146, 3097-3122, https://doi.org/10.1175/MWR-D-18-0059.1.

Karyampudi, V. M., S. E. Koch, C. Chen, and J. W. Rottman, 1995: The influence of the Rocky Mountains on the 13-14 April 1986 severe weather outbreak. Part II: Evolution of a prefrontal bore and its role in triggering a squall line. Mon. Wea. Rev., 123, 1423-1446, https://doi.org/10.1175/1520-0493(1995)123<1423: TIOTRM $>2.0 . \mathrm{CO} ; 2$.

Knupp, K. R., 2006: Observational analysis of a gust front to bore to solitary wave transition within an evolving nocturnal boundary layer. J. Atmos. Sci., 63, 2016-2035, https://doi.org/ 10.1175/JAS3731.1.

—_, R. Wade, A. W. Lyza, and S. M. Wingo, 2016: Comparison of estimates of vertical motion from vertically-pointing lidar and radar within gust fronts, bores, and low-level gravity waves. 18th Symp. on Meteorological Observation and Instrumentation, New Orleans, LA, Amer. Meteor. Soc., 5.2, https://ams.confex.com/ams/96Annual/webprogram/ Paper290321.html.

Knuteson, R. O., and Coauthors, 2004a: Atmospheric Emitted Radiance Interferometer (AERI). Part I: Instrument design. J. Atmos. Oceanic Technol., 21, 1763-1776, https://doi.org/ 10.1175/JTECH-1662.1.

, and Coauthors, 2004b: Atmospheric Emitted Radiance Interferometer (AERI). Part II: Instrument performance. J. Atmos. Oceanic Technol., 21, 1777-1789, https://doi.org/ 10.1175/JTECH-1663.1.

Koch, S. E., and W. L. Clark, 1999: A nonclassical cold front observed during COPS-91: Frontal structure and the process of severe storm initiation. J. Atmos. Sci, 56, 2862-2890, https://doi.org/ 10.1175/1520-0469(1999)056<2862:ANCFOD>2.0.CO;2.

_ , P. B. Dorian, R. Ferrare, S. H. Melfi, W. C. Skillman, and D. Whiteman, 1991: Structure of an internal bore and dissipating gravity current as revealed by Raman lidar. Mon. Wea. Rev., 119, 857-887, https://doi.org/10.1175/1520-0493(1991)119<0857: SOAIBA $>2.0 . \mathrm{CO} ; 2$.

, W. F. Feltz, F. Fabry, M. Pagowski, B. Geerts, K. M. Bedka, D. O. Miller, and J. W. Wilson, 2008: Turbulent mixing processes in atmospheric bores and solitary waves deduced from profiling systems and numerical simulation. Mon. Wea. Rev., 136, 1373-1400, https://doi.org/10.1175/2007MWR2252.1.

Lindseth, B., W. O. J. Brown, J. Jordan, D. Law, T. Hock, S. A. Cohn, and Z. Popović, 2012: A new portable 449-MHz spaced antenna wind profiler radar. IEEE Trans. Geosci. Remote Sens., 50, 3544-3553, https://doi.org/10.1109/TGRS.2012.2184837.

Locatelli, J. D., M. T. Stoelinga, and P. V. Hobbs, 2002: A new look at the Super Outbreak of tornadoes on 3-4 April 1974. Mon. Wea. Rev., 130, 1633-1651, https://doi.org/10.1175/ 1520-0493(2002)130<1633:ANLATS > 2.0.CO;2.
Mahapatra, P. R., R. J. Doviak, and D. S. Zrnic, 1991: Multisensor observation of an atmospheric undular bore. Bull. Amer. Meteor. Soc., 72, 1468-1480, https://doi.org/10.1175/ 1520-0477(1991)072<1468:MOOAAU > 2.0.CO;2.

Morse, C. S., R. K. Goodrich, and L. B. Cornman, 2002: The NIMA method for improved moment estimation from Doppler spectra. J. Atmos. Oceanic Technol., 19, 274-295, https://doi.org/ 10.1175/1520-0426-19.3.274.

Mueller, D., B. Geerts, Z. Wang, M. Deng, and C. Grasmick, 2017: Evolution and vertical structure of an undular bore observed on 20 June 2015 during PECAN. Mon. Wea. Rev., 145, 37753794, https://doi.org/10.1175/MWR-D-16-0305.1.

Parker, M. D., 2008: Response of simulated squall lines to low-level cooling. J. Atmos. Sci., 65, 1323-1341, https://doi.org/10.1175/ 2007JAS2507.1.

Parsons, D. B., K. R. Haghi, K. T. Halbert, B. Elmer, and J. Wang, 2019: The potential role of atmospheric bores and gravity waves in the initiation and maintenance of nocturnal convection over the Southern Great Plains. J. Atmos. Sci., 76, 43-68, https://doi.org/10.1175/JAS-D-17-0172.1.

Pearson, G., F. Davies, and C. Collier, 2009: An analysis of the performance of the EFAM pulsed Doppler lidar for observing the boundary layer. J. Atmos. Oceanic Technol., 26, 240-250, https://doi.org/10.1175/2008JTECHA1128.1.

Rottman, J. W., and J. E. Simpson, 1989: The formation of internal bores in the atmosphere: A laboratory model. Quart. J. Roy. Meteor. Soc., 115, 941-963, https://doi.org/10.1002/ qj.49711548809.

Scintec, 2017: Radar wind profiler LAP3000, $915 \mathrm{MHz}, 4$ panels. Accessed 1 November 2017, http://www.scintec.com/english/ web/Scintec/Details/A050002.aspx.

Sisterson, D. L., R. A. Peppler, T. S. Cress, P. J. Lamb, and D. D. Turner, 2016: The ARM Southern Great Plains (SGP) site. The Atmospheric Radiation Measurement Program: The First 20 Years, Meteor. Monogr., No. 57, Amer. Meteor. Soc., 6.1-6.14, https://doi.org/10.1175/AMSMONOGRAPHS-D-16-0004.1.

Smith, R. K., 1988: Travelling waves and bores in the lower atmosphere: The 'Morning Glory' and related phenomena. Earth-Sci. Rev., 25, 267-290, https://doi.org/10.1016/ 0012-8252(88)90069-4.

— N. Crook, and G. Roff, 1982: The Morning Glory: An extraordinary atmospheric undular bore. Quart. J. Roy. Meteor. Soc., 108, 937-956, https://doi.org/10.1002/qj.49710845813.

Tanamachi, R. L., W. F. Feltz, and M. Xue, 2008: Observations and numerical simulation of upper boundary layer rapid drying and moistening events during the International $\mathrm{H}_{2} \mathrm{O}$ Project (IHOP_2002). Mon. Wea. Rev., 136, 3106-3120, https://doi.org/10.1175/2008MWR2204.1.

Toms, B. A., J. M. Tomaszewski, D. D. Turner, and S. E. Koch, 2017: Analysis of a lower-tropospheric gravity wave train using direct and remote sensing measurement systems. Mon. Wea. Rev., 145, 2791-2812, https://doi.org/10.1175/ MWR-D-16-0216.1.

Turner, D. D., 2016a: FP3 AERIoe thermodynamic profile retrieval data (version 2.0). UCAR/NCAR Earth Observing Laboratory, accessed 14 August 2017, https://doi.org/10.5065/D6Z31WV0. , 2016b: FP4 AERIoe thermodynamic profile retrieval data (version 2.0). UCAR/NCAR Earth Observing Laboratory, accessed 14 August 2017, https://doi.org/10.5065/D6PN93T3. , 2016c: MP1 OU/NSSL CLAMPS AERIoe thermodynamic profile retrieval data (version 1.0). UCAR/NCAR Earth Observing Laboratory, accessed 12 September 2016, https:// doi.org/10.5065/D6VQ312C. 
2016d: MP1 OU/NSSL CLAMPS Doppler Lidar VAD wind data (version 1.0). UCAR/NCAR Earth Observing Laboratory, accessed 7 July 2016, https://doi.org/10.5065/D6BR8QJH.

— in thermodynamic profiles and liquid cloud properties retrieved from the ground-based Atmospheric Emitted Radiance Interferometer (AERI). J. Appl. Meteor. Climatol., 53, 752-771, https://doi.org/10.1175/JAMC-D-13-0126.1.

__ , and W. G. Blumberg, 2019: Improvements to the AERIoe thermodynamic profile retrieval algorithm. IEEE J. Sel. Top. Appl. Earth Obs. Remote Sens., https://doi.org/10.1109/ JSTARS.2018.2874968, in press.

—, R. O. Knuteson, H. E. Revercomb, C. Lo, and R. G. Dedecker, 2006: Noise reduction of Atmospheric Emitted Radiance Interferometer (AERI) observations using principal component analysis. J. Atmos. Oceanic Technol., 23, 1223-1238, https://doi.org/10.1175/JTECH1906.1.

UCAR/NCAR Earth Observing Laboratory, 2015: FP4 NCAR/ EOL $915 \mathrm{MHz}$ profiler NIMA consensus winds and moments (version 1.0). UCAR/NCAR Earth Observing Laboratory, accessed 10 October 2016, https://doi.org/10.5065/D6RV0KXH.

, 2017: FP3 NCAR/EOL 449MHz profiler 30 minute consensus winds data (version 1.0) [PRELIMINARY]. UCAR/NCAR Earth Observing Laboratory, accessed 10 October 2016, https:// doi.org/10.5065/D66W98T7.

Wagner, T. J., W. F. Feltz, and S. A. Ackerman, 2008: The temporal evolution of convective indices in storm-producing environments. Wea. Forecasting, 23, 786-794, https://doi.org/ 10.1175/2008WAF2007046.1.

_, E. Olson, N. Smith, and W. F. Feltz, 2016a: MP3 University of Wisconsin SPARC AERIoe thermodynamic profile data (version 1.0). UCAR/NCAR Earth Observing Laboratory, accessed 2 October 2016, https://doi.org/10.5065/ D60Z71HC.

_ D. D. Turner, and R. Newsom, 2016b: MP3 University of Wisconsin SPARC Doppler Lidar VAD wind data (version 2.0). UCAR/NCAR Earth Observing Laboratory, accessed 10 October 2016, https://doi.org/10.5065/D6V9869B.

— , P. M. Klein, and D. D. Turner, 2019: A new generation of ground-based mobile platforms for active and passive profiling of the boundary layer. Bull. Amer. Meteor. Soc., 100, 137-153, https://doi.org/10.1175/BAMS-D-17-0165.1.

Wakimoto, R. M., and D. E. Kingsmill, 1995: Structure of an atmospheric undular bore generated from colliding boundaries during CAPE. Mon. Wea. Rev., 123, 1374-1393, https://doi.org/ 10.1175/1520-0493(1995)123<1374:SOAAUB > 2.0.CO;2.

Wallace, J. M., 1975: Diurnal variations in precipitation and thunderstorm frequency over the conterminous United States. Mon. Wea. Rev., 103, 406-419, https://doi.org/10.1175/ 1520-0493(1975)103<0406:DVIPAT>2.0.CO;2.

Wilson, J. W., and R. D. Roberts, 2006: Summary of convective storm initiation and evolution during IHOP: Observational and modeling perspective. Mon. Wea. Rev., 134, 23-47, https:// doi.org/10.1175/MWR3069.1. 